\title{
Guidebook for Standards-Based Testing of Radiation-Detection Systems
}

L. Pibida

C. Forrester

P. Chiaro

D. Potter

This publication is available free of charge from:

https://doi.org/10.6028/NIST.TN.2073

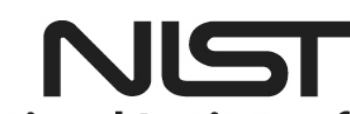

National Institute of Standards and Technology U.S. Department of Commerce 


\title{
Guidebook for Standards-Based Testing of Radiation-Detection Systems
}

\author{
L. Pibida \\ Radiation Physics Division \\ Physical Measurement Laboratory \\ C. Forrester \\ Oak Ridge National Laboratory \\ P. Chiaro \\ IB3 Global Solutions \\ D. Potter
}

Countering Weapons of Mass Destruction Office

This publication is available free of charge from:

https://doi.org/10.6028/NIST.TN.2073

November 2019

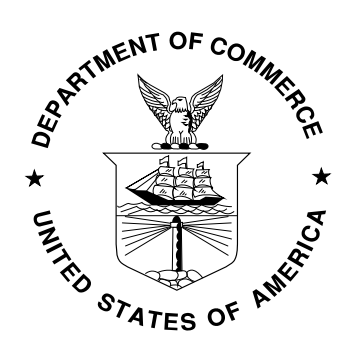

U.S. Department of Commerce Wilbur L. Ross, Jr., Secretary

National Institute of Standards and Technology Walter Copan, NIST Director and Undersecretary of Commerce for Standards and Technology 
Certain commercial entities, equipment, or materials may be identified in this document in order to describe an experimental procedure or concept adequately. Such identification is not intended to imply recommendation or endorsement by the National Institute of Standards and Technology, nor is it intended to imply that the entities, materials, or equipment are necessarily the best available for the purpose.

National Institute of Standards and Technology Technical Note 2073 Natl. Inst. Stand. Technol. Tech. Note 2073, 58 pages (November 2019) CODEN: NTNOEF

This publication is available free of charge from: https://doi.org/10.6028/NIST.TN.2073 


\title{
Guidebook for Standards-Based Testing of Radiation-Detection Systems
}

\author{
L. Pibida ${ }^{1}$, C. Forrester ${ }^{2}$, P. Chiaro ${ }^{3}$ and D. Potter 4 \\ ${ }^{1}$ National Institute of Standards and Technology, 100 Bureau Drive, Gaithersburg, MD 20899-8462 \\ 2 Oak Ridge National Laboratory, 1 Bethel Valley Road, Oak Ridge, TN 37831 \\ ${ }^{3}$ IB3 Global Solutions, 97 Midway Lane, Oak Ridge, TN 37830 \\ ${ }^{4}$ Countering Weapons of Mass Destruction Office, 1120 Vermont Ave NW, Washington DC 20005
}

\begin{abstract}
This guide describes the test setups and processes needed to perform standards-based testing of radiological and nuclear detection systems. This guide is intended to reduce the potential for misinterpretation of performance requirements, test methods, and to improve uniformity of testing methods used at different testing organizations.

This guide does not address safety concerns, if any, associated with its use. It is the responsibility of the user of this guide to establish appropriate safety and health practices and determine the applicability of regulatory limitations prior to use.
\end{abstract}

Keywords: radiation detection for homeland security, ANSI N42 standards, testing of radiation detection equipment, testing guidance

† Corresponding author: leticia.pibida@nist.gov 


\section{Table of Contents}

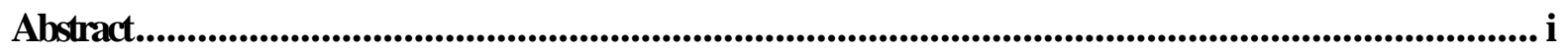

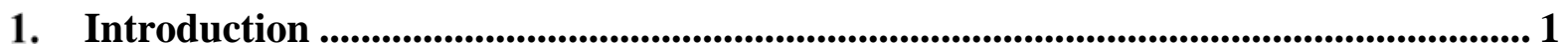

2. Significance and use.............................................................................................................. 1

3. General ........................................................................................................................... 1

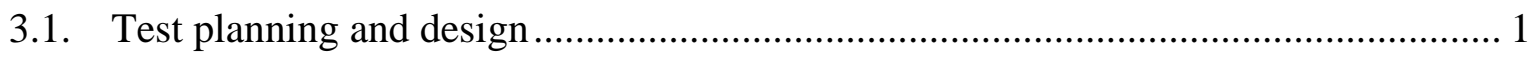

3.2. Categories of equipment under test (EUT) ............................................................. 3

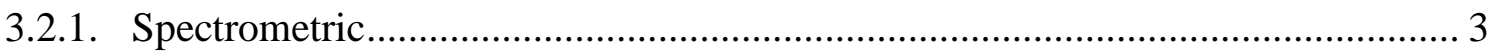

3.2.2. Non-spectrometric ....................................................................................... 3

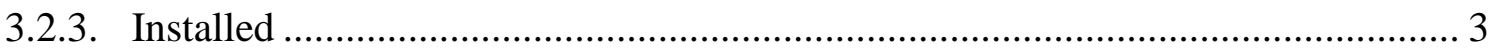

3.2.4. Modular equipment ................................................................................ 3

3.3. Test documentation and system configuration control............................................... 4

3.4. Test documentation - Reporting ........................................................................ 4

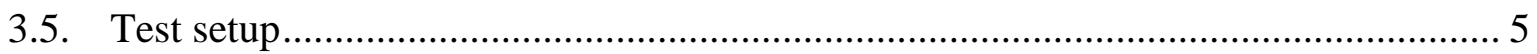

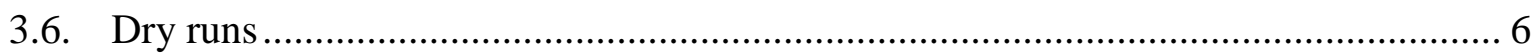

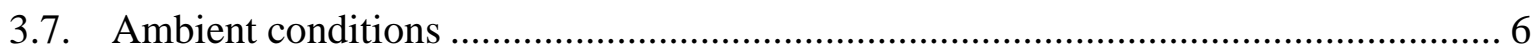

3.7.1. Performing tests outside of standard test conditions ............................................ 6

3.8. Radiation test-field measurement ........................................................................ 7

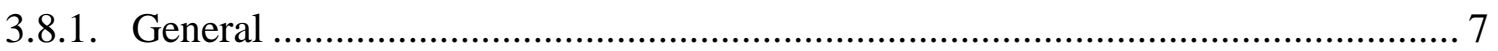

3.8.2. Exposure rate and dose equivalent rate measurements ........................................ 8

3.8.3. Fluence rate measurement .............................................................................. 8

3.8.4. Establish exposure rate/fluence rate uncertainties.................................................. 9

3.8.5. Establish a background monitoring frequency ……............................................. 10

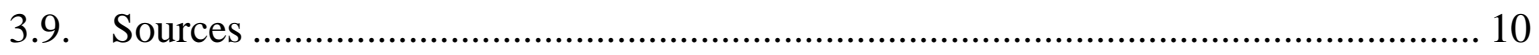

3.9.1. Traceability .................................................................................................. 10

3.9.2. Source housing or encapsulation - Gamma sources ............................................ 11

3.9.3. Source use life - Gamma sources........................................................................ 11

3.9.4. Neutron Sources ............................................................................................. 12

3.9.5. Radionuclide identification measurements - impurities ........................................ 14

3.10. Coefficient of variation ................................................................................... 14

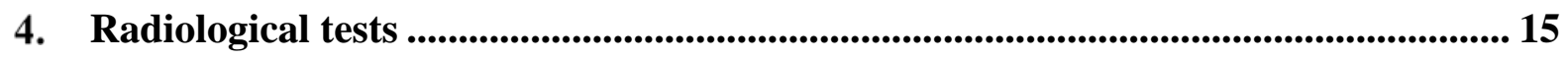

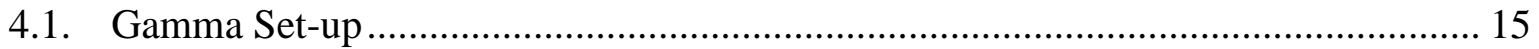




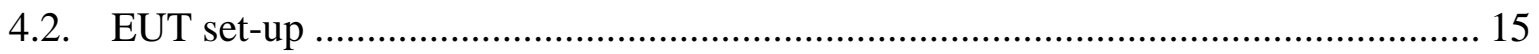

4.2.1. Static measurements ................................................................................... 16

4.2.2. Dynamic measurements ............................................................................. 16

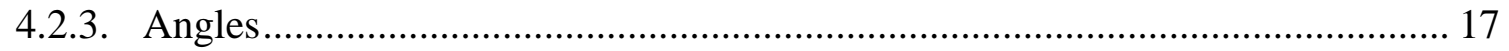

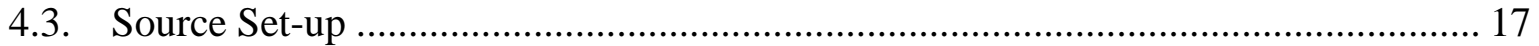

4.4. Medicals/Short-Lived Radionuclides ................................................................... 17

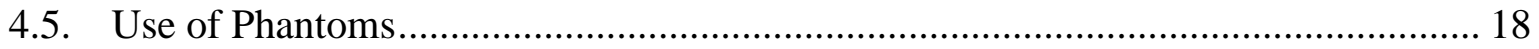

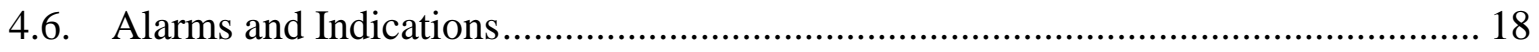

4.7. EUT Communication and File Creation................................................................. 19

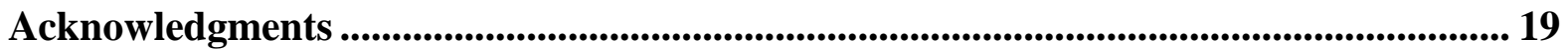

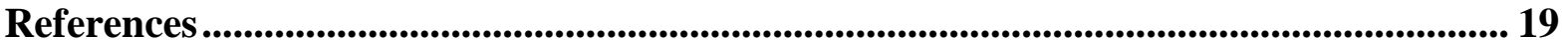

Appendix A: Exposure and ambient dose equivalent rate calculations ............................. 20

Appendix B: Fluence rate and efficiency calculations........................................................ 33

Appendix C: Identifying mutually orthogonal (perpendicular) planes.............................. 41

Appendix D: List of standards.............................................................................................. 42

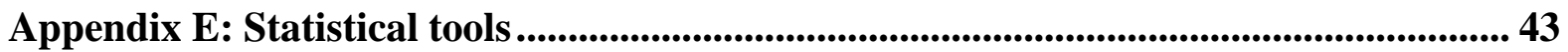

\section{List of Tables}

Table A.1: Probabilities per disintegration for ${ }^{232} \mathrm{Th}$ and ${ }^{226} \mathrm{Ra}$ (in equilibrium) as a function

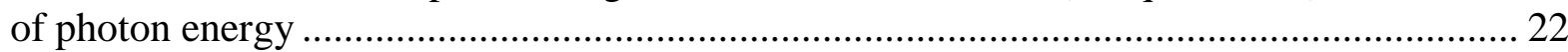

Table A.2: Values of the mass energy-transfer, mass energy-absorption, and mass attenuation coefficients for air ........................................................................................... 23 Table A.3: Conversion coefficient $h \mathrm{~K} *(10)$ from air kerma, $K$, to ambient dose equivalent, $H^{*}(10)$, for mono-energetic and parallel photon beams ...................................................... 26 Table A.4: Probabilities per disintegration for ${ }^{232} \mathrm{Th}$ and ${ }^{226} \mathrm{Ra}$ (in equilibrium) as a function

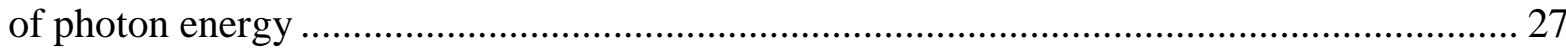

Table A.5: Values of the mass energy-transfer and mass attenuation coefficients for air.... 29 Table E.6: The required number of measurements and associated test criteria to maintain equivalent level of scrutiny when the coefficient of variation exceeds the required maximum of $8 \%$.

\section{List of Figures}

Figure 1: Test setup for exposure rate measurements. 8

Figure 2: Relationship between minimum allowable tolerance and minimum frequency of adjustment.

Figure 3: Energy response from a pressurized-ion chamber when measured from side, front and marked face of the instrument. 
Figure 4: Energy response provided by the instrument manual and the calibration values from a pressurized-ion chamber. Uncertainty values are not provided in the instrument manual, the uncertainties in the y-axis NIST values smaller than the symbol size, uncertainties are given with a coverage factor of $k=1$.

Figure 5: Full-energy peak efficiency curve for HPGe detector and associated fitting curve. Uncertainties are smaller than the symbol size, uncertainties are given with a coverage factor of $k=1$. 36

Figure 6: Residuals from polynomial fit to full-energy peak efficiency curve for HPGe ..... 36

Figure 7: Cartesian coordinate system...................................................................... 41 Figure 8: Estimated probability of accepting an instrument under the hypothesis test when $\mu_{\text {pre }}=100$ and $\mathrm{n}_{1}=\mathrm{n}_{2}=10$ for $\mathrm{V}=12 \%$ (top), $\mathrm{V}=8 \%$ (middle), and $\mathrm{V}=2 \%$ (bottom) with levels of significance $\alpha=0.05,0.10$, and 0.20 . 47 


\section{Terminology definitions and glossary}

\section{Definitions}

Alarm - An audible, visual, or other signal activated when the instrument reading or response exceeds a preset value or falls outside of a preset range.

Background - Radiation signature of test area surroundings with no external sources present.

Calibrate - To adjust or determine the response or reading of a device relative to a series of conventionally true values.

Coefficient of variation - The square root of the sample variance, $\sigma^{2}$, divided by the mean value of " $n$ " number of readings multiplied by 100, expressed in \%.

Dead-time - The amount of time after an event during which the system is not able to record another event.

Detect - To discover or determine the existence of a material or item of interest.

Dose equivalent - A quantity used in radiation protection. It is defined as the product of the absorbed dose and certain modifying factors (the unit of dose equivalent is rem or Sv). See ICRU Report 39 and 47 for additional details.

Dose equivalent rate - The radiation dose delivered per unit of time.

Exposure rate - The measure of ionization produced in air by $\mathrm{x}$-ray or gamma-ray radiation.

Fluence rate - The number of particles that interact with a defined cross-sectional area of a sphere $\left(\mathrm{cm}^{2}\right)$ over a defined time period $\left(\mathrm{s}^{-1}\right)$.

Functional tests - Tests performed to verify the ability of an element or component of an element to continue to be used for its intended purpose.

Geometry (calibration or measurement) - The source-instrument setup including distance, position of source in reference to the instrument, shape of source, matrix material, and encapsulation.

High purity germanium (HPGe) detector - A solid-state semiconductor type detector utilizing a hyper-pure high purity germanium crystal, operated at liquid nitrogen temperatures, used for high-resolution, gamma-ray spectrometry.

Installed equipment - Radiation equipment permanently mounted at a location for use.

Jig - Device used to position a test source or the equipment under test (EUT) such that calibration or functional checks are repeatable.

Measurement and Test Equipment (M\&TE) - Laboratory owned equipment used to ensure the accuracy and precision of the recorded data.

Modular equipment - Radiation equipment designed to have a flexible architecture for various situations, which includes adding or removing detectors and accessories.

Phantom - A slab of polymethyl methacrylate (PMMA) typically with a thickness of $15 \mathrm{~cm}$ and a face no smaller than $30 \mathrm{~cm} \times 30 \mathrm{~cm}$. 
Radionuclide - Radioactive isotope of an element.

Response check - A test of the instrument using known radiation sources to verify functionality.

Quality control - A system of actions that keep the quality of goods or services at the level expected by their users.

Source emission rate - Number of particles of a given type and energy emitted by a radioactive source per unit time.

Survey instrument - A handheld device used to measure the amount and locate hazardous material, hazardous material contamination, and hazardous conditions.

Test campaign - An effort involving the testing of more than one EUT to the same test plan.

Test plan - Document developed between the testing entity and customer containing testing requirements, test methods, and performance indicators.

Traceable - In reference to a calibration standard, the properties of which can be related back to a national standard by NIST or equivalent organization.

\section{Glossary}

AC

ALARA

ANSI

BRD

CDN

CONOPS

COV

EUT

GPS

HPGe

IEC

NIST

NORM

PRD

PMMA

POV

PTB

PVT

RF

RID

RPM

SNM
Alternating Current

As Low As Reasonably Achievable

American National Standards Institute

Backpack-Based Radiation Detector

Coupling/Decoupling Network

Concept of Operations

Coefficient of Variation

Equipment Under Test

Global Positioning System

High Purity Germanium

International Electrotechnical Commission

National Institute of Standards Technology

Naturally Occurring Radioactive Material

Personal Radiation Detector

Polymethyl Methacrylate

Personally Owned Vehicle

Physikalisch-Technische Bundesanstalt

Polyvinyl Toluene

Radio Frequency

Radionuclide Identification Device

Radiation Portal Monitor

Special Nuclear Material 


\begin{tabular}{|ll} 
SPRD & Spectroscopic Personal Radiation Detector \\
SRPM & Spectroscopy-Based Radiation Portal Monitor \\
US & United States of America \\
WGPu & Weapons-Grade Plutonium \\
$\mathbf{Z}$ & Atomic number
\end{tabular}




\section{Introduction}

The Radiological and Nuclear Detection community uses instruments to detect and identify radiological material. These instruments require proper testing to verify that they meet the requirements established in several consensus and technical capability standards for radiation detection instruments used in homeland security applications.

For radiation detection systems, test setup, and measurement and test equipment (M\&TE) can have a significant impact on an instrument's response and can result in test results not accurately reflecting an instrument's true performance capabilities. This document provides guidance regarding the setup of tests and the use of M\&TE when performing tests against radiological/nuclear detection equipment standards.

\section{Significance and use}

This guide addresses standards-established radiological and functionality performance test methods that have been identified as areas of most concern regarding test performance and reproducibility. This guide is applicable to testing performed against criteria found in US and international consensus standards (i.e., ANSI, IEC), and US government unique standards (i.e., Technical Capability Standards).

Guidance when performing climatic, mechanical, and electromagnetic performance test methods can be found in the IEC 62706 standard.

\section{General}

\subsection{Test planning and design}

Consideration should be given to developing a test plan detailing the tests to be performed, including specific sources (radionuclide and activity) that will be used for each test; methods used to verify source activity or exposure/dose equivalent rate; facilities that will be used; operating parameters for the instrument to be tested; order of testing; data collection methods; and data that will be documented for each test.

Radiation detection system testing performed against consensus standards often requires the use of multiple sources, equipment configurations, testing modes (for example, static, dynamic), and source transport devices. It is advisable to create a master matrix that reflects the range of test permutations. This matrix can be used to optimize and coordinate resources. For example, it may be more efficient to perform multiple tests using one source at a time, or to run all sources through one test before moving on to the next test.

Testing is typically structured from least to most severe potential distress to the equipment under test (EUT). Most testing is divided up into fundamentally three different groups:

1. General - documenting design, functional requirements and operating modes.

2. Radiological - radiation detection or identification capabilities. 
3. Immunity - immunity to changing climatic conditions, exposure to various electrical perturbations and environments, and mechanical extremes.

Test planning steps should be categorized in advance as nondestructive or potentially destructive to inform the test order. Potentially destructive tests may damage systems or result in loss of functionality that is not recoverable without repairs or replacements. Conduct tests considered as nondestructive before tests considered potentially destructive.

When a standard requires false alarm testing, the test should be performed prior to radiological testing and should be performed in the same or similar radiation background to the background that will be present during radiological testing. Parameters established during false alarm testing should be used for the remaining radiological testing. Any adjustments performed midway through a test must have no effect on test results that have already been completed. If adjustments are made and an impact is known or cannot be ruled out, the previous test data should be considered invalidated and repeated using the new parameter settings.

Generally, mechanical performance testing (for example, impact, drop, and vibration) is considered potentially destructive and should be completed after other test steps. The list below is a recommended order of testing from non-destructive tests to tests potentially damaging the EUT.

- General tests

- Radiological tests

- Overload or over-range test should be the last conducted radiological test

- RF emissions

- RF immunity

- Magnetic field

- Ambient temperature

- Humidity

- Conducted disturbances

- AC line voltage

- Surges and oscillatory waves

- Impact

- Dust

- Electrostatic discharge

- Vibration

- Moisture

- Shock/drop

- $\quad$ Salt fog 


\subsection{Categories of equipment under test (EUT)}

\subsubsection{Spectrometric}

Spectrometric devices have the ability to identify individual radionuclides from the gamma spectrum. For example, a spectrometric device would not only be able to indicate the detection of a gamma-ray emitting source but also to identify the specific radionuclide. Some spectrometric devices can also measure accumulated gamma radiation dose.

Equipment suppliers can typically change system performance to meet customer alarm and CONOPS requirements (such as, different libraries, algorithms, or thresholds). Early definition of end use requirements and desired CONOPS is advised and will help to streamline and focus test planning and execution.

\subsubsection{Non-spectrometric}

Non-spectrometric refers to devices that focus solely on measuring radioactivity levels and alarm once they detect a gamma or neutron field above a particular threshold. This is considered the default capability of a radiological detection device. These units will only detect, not identify the source of gamma radiation.

The alarm thresholds should be set by the manufacturer and not changed throughout the testing campaign.

\subsubsection{Installed}

An installed device refers to a permanently installed equipment. By virtue of the larger size of the detector elements, installed devices provide more detection range and sensitivity than handheld detectors. Systems can be installed for a wide variety of applications including the monitoring of streams of traffic. For example, pedestrian (i.e., airport/stadium/building entrance), vehicular (i.e., POV), or commercial (i.e., truck, cargo container).

For tests where the source is in motion, the mechanism used to move the source should be documented (for example, simulated cargo, truck length, etc.).

If installed systems are tested as individual components, the components should be configured to match the installation configuration to the extent possible. Deviations should be documented (for example, cable lengths, software modifications to facilitate testing, shielding shrouds, etc.).

\subsubsection{Modular equipment}

Modular equipment consists of multiple components that can be configured in a variety of ways (for example, number and types of detectors, user interface). An example of modular equipment is a backpack device with multiple gamma and neutron sensor configurations.

Modular equipment setup needs to include all the modules that make a complete detection instrument, all of the modules' serial numbers need to be recorded, and the set must remain together for all testing phases. The complete detection system not only includes the individual modules but also includes any cabling used to connect modules together. Once all testing phases have been completed, additional testing can take place to determine the effect on test results by module swapping or other interface changes. 


\subsection{Test documentation and system configuration control}

Test documentation should be controlled via version control. Version control should include a process for tracking changes. In general, the change control process should describe when changes are allowed, how they may be made, and what approvals are needed to implement testing per the new revision of the documentation.

The EUT may be set up and configured by the testing organization or by the manufacturer. In either case, a checklist should be used to document system configuration and settings prior to testing including algorithm and hardware settings as applicable. This documentation may be used to establish formal configuration control. When the manufacturer is present, it is advisable for them to perform the checklist items, and formally sign off that the system is ready for testing. This establishes the manufacturer as accountable for system configuration. If any of the settings are changed after this point, the checklist should be revised to indicate the new configuration and appropriate approvals obtained through checklist signoff. The test team should assess whether test actions must be re-performed based on the configuration change, or whether the prior testing is independent of the change made.

Pre-test system configuration should be established using a comprehensive system turnover checklist. It is preferable to have the equipment supplier create the turnover checklist, but, in some cases, the testing organization may have to create one. At a minimum, the checklist should include provisions for documenting EUT components, serial numbers, version numbers, software and firmware versions, system settings, interface configurations, performance status, and readiness for turnover to the testing organization.

Under ideal circumstances, the equipment supplier should be responsible for setting up and configuring the equipment, and for performing the turnover checklist tasks with oversight from the testing organization.

For EUTs with different possible configurations and various accessories (for example, additional detector probes, GPS, phone connections, etc.), consistent testing configurations should be established and documented, with exceptions noted. For example, different configurations can result in changes to attenuation and scatter factors. The configurations under test, including whether the source or detector is in motion, must be documented.

Software and firmware versions of the EUT should, if known, be recorded as part of the test documentation. Unless there is a pre-planned need for testing older versions, EUT systems should have the most current software/firmware versions for consistency. Unless planned in advance and formally documented in test documentation, changes in software/firmware versions should not be made after the test has started.

\subsection{Test documentation - Reporting}

Each EUT should be labeled with a unique identifier to allow easy identification in photographs taken in different orientations. 
It is a good practice to include photos as part of the test setup documentation. Photos should clearly show each EUT being tested, the source location, reference points, and other details. Use of a placard to record test parameters and conditions helps assure that each photo is associated with the correct test. The relevant details of a particular test (for example, source identifier, date, time, test trial number, etc.) can be written on the placard. The placard is then placed in front of the EUT, and the information is recorded in a photo.

Labels should be affixed as close as possible to the EUT's display to make it easy to identify which EUT's display is being photographed. Best possible cases would be one label above the display and one label below the display, so a label will always be in the picture if zooming in for a tight shot is necessary.

Data collection should be commensurate of the test plan. If automated data collection is used, measures should be taken to ensure the data collection does not interfere with the process that the EUT uses to collect and store data. For example, data collection systems that require software/hardware penetration to collect the data should be evaluated before using. Whenever possible, external sensors should be used to monitor the EUTs' normal user indications. This eliminates the need and risk of penetrating the EUT or altering default software to make testing easier.

If an automatic data collection system is being used, users should verify that the system is recording the desired data at the required frequency.

Time synchronization is important for quality assurance, data review, and validation purposes. The frequency and precision of the time synchronization depends on the test type and equipment capability.

Networked test equipment such as video cameras, PCs, and data collection systems can be automatically time synchronized to the same server to allow data reviewers to find related test information quickly. Networked devices can usually maintain a time synchronization to within a second of each other.

Non-networked equipment, such as handheld cameras, reference detectors, and the EUTs themselves should be time synchronized as required to keep the time within reasonable deviation for the type of testing being performed.

\subsection{Test setup}

In many cases, test sources are placed at a static location in proximity to the EUT or are attached to a device that transits the area in a dynamic mode (for example, simulating a source in a passing car, etc.). Temporary markings such as paint, chalk, or tape may be used to establish exact source or instrument placement for reproducibility. If dynamic runs are performed using a manned vehicle, a paint or tape stripe down the lane may improve location accuracy. 


\subsection{Dry runs}

In a formal test event, preparation activities may include a dry run. This event helps ensure that the EUTs are properly integrated into the test environment, test personnel are familiar with the use of the EUTs and the lab equipment, the test procedures are executable, and data acquisition is occurring as designed.

A dry run is an informal execution of all or part of each test plan. A dry run is mainly used as an initial vetting of the test plan and equipment to identify major issues. Upon completion of the dry run, the test plan and equipment may be adjusted per the lessons learned. Additional dry runs may be needed to verify the changes addressed the identified issues. Where possible, the actual test sources should be used in the dry runs.

Any adjustments or changes to the test equipment or test procedures after, and as a result of the dry run, should be small and not alter the conduct of the test to a significant degree (for example, fixing typographical errors, reordering steps for increased efficiency, etc.). Additional testing efficiency may be achieved by taking into account the results of the test when actual tests are performed during the dry run.

\subsection{Ambient conditions}

Ambient conditions (for example, temperature, pressure, humidity, etc.) including radiation background should be recorded at the beginning of each test, continuously monitored, and logged at an appropriate time interval.

Radiation sources, including those that may be located inside the in laboratory equipment around the vicinity of the EUT, can become part of the EUT background spectra and cause erroneous test results. To ensure all radiation sources are properly shielded or removed from the vicinity of the EUT, an HPGe system must be used to take background spectra at the test locations of the EUT. Review the spectra within the laboratory and take appropriate measures to reduce the source presence in the background, if necessary. This process should be used anytime a new source is introduced in to the facility.

\subsubsection{Performing tests outside of standard test conditions}

Most consensus standards require testing to be performed within a range of standard test conditions. It is recommended when performing a test that the ambient conditions are within range before, during, and after testing.

At times, it is necessary to perform testing outside of standard test conditions (for example, testing large devices outdoors). If testing is carried out in an uncontrolled environment (e.g., outdoors) the temperature, humidity, atmospheric pressure, and weather conditions (e.g., rain, snow) needs to be recorded hourly throughout the duration of the tests. In addition, the detection system stability is measured over the duration of the test period as follows:

- The temperature is constantly monitored throughout the duration of the test. If testing is performed in an uncontrolled environment (i.e., no temperature or humidity control or weather protection), a stability measurement is carried out to record any changes in the detection system response if the temperature varies by more than $\pm 10{ }^{\circ} \mathrm{C}$ from the 
measured temperature range at the start of the test. The system response is recorded when the temperature is outside this pre-determined range.

- The temperature range is determined from a full day of temperature measurements performed prior to the start of the test (refer to as pre-test). With the ${ }^{57} \mathrm{Co}$ and ${ }^{60} \mathrm{Co}$ sources, placed on a tripod (or similar mounting fixture without shielding each other) centered in front of the system, monitor the system count rate over the course of the day. Changes in the detection system count rate should be less than $\pm 20 \%$. Record the minimum and maximum temperatures for the day as the temperature range.

- If the temperature is outside the pre-determined range, the detection system response is verified by placing the ${ }^{57} \mathrm{Co}$ and ${ }^{60} \mathrm{Co}$ sources (together as in the pre-test), on a tripod (or similar mounting fixture) centered in front of the detection system. Acquire a 5 minute static source measurement by measuring the count rate; calculate the mean count rate and standard deviation. Remove the sources and acquire a 5 minute background by measuring the count rate; calculate the mean count rate and standard deviation. Record these values. The detection system response needs to be within $\pm 20 \%$ of the average response recorded when the temperature range was established.

- If spectral data are collected by the detection system, these data are recorded for the background and source measurements described above.

If the response check is substantially different, testing should not be performed until consulting with the manufacturer.

\subsection{Radiation test-field measurement}

\subsubsection{General}

The instruments used to measure radiation fields should have a calibration that is traceable. Sources may be directly traceable or traceable through use of a calibrated instrument (for example, pressurized ion chamber) with a traceable calibration. For example:

- Traceable sources are acquired from source manufacturers and/or sources are calibrated by national metrology institutes (e.g., NIST, PTB, NPL)

- Instrument are calibrated by national metrology institutes or secondary calibration laboratories and the instrument response as a function of energy need to be measured

- Instruments are calibrated at the testing laboratory using traceable sources

A radiation field from the radiation test sources can be specified by the exposure rate, dose equivalent rate, source emission rate, source activity, or fluence rate (for example, $50 \mu \mathrm{R} / \mathrm{h}$, $50 \mu \mathrm{Sv} / \mathrm{h}, 20000 \mathrm{~s}^{-1}, 250 \mathrm{kBq}, 0.9 \mathrm{~cm}^{-2} \mathrm{~s}^{-1}$ respectively). Conversion of known source values (such as activity or mass) to radiation fields used for testing (such as exposure rate, dose equivalent rate, or fluence rate) requires knowledge of the energy spectrum and measurement geometry and should be accomplished through measurement and/or calculation (see Appendix A).

If the calibrated measurement device or the EUT are calibrated in different units than they are used to specify the radiation field for testing, the appropriate conversion factors should be applied (see Appendix A). 


\subsubsection{Exposure rate and dose equivalent rate measurements}

It is recommended to use a pressurized ion chamber that is being calibrated using traceable sources and/or radiation beams (e.g., traceable x-ray beams) with a known energy response function, as the calibrated device for exposure rate measurements. Measurements should be performed with the calibrated device in the manufacturer-recommended or calibrated orientation. (In order to convert from dose equivalent rate to exposure rate, see ISO 4037-3, ICRU-57, and examples in Appendix A.) The instrument reference point should be used for source-to-detector distance measurements (see Figure 1).

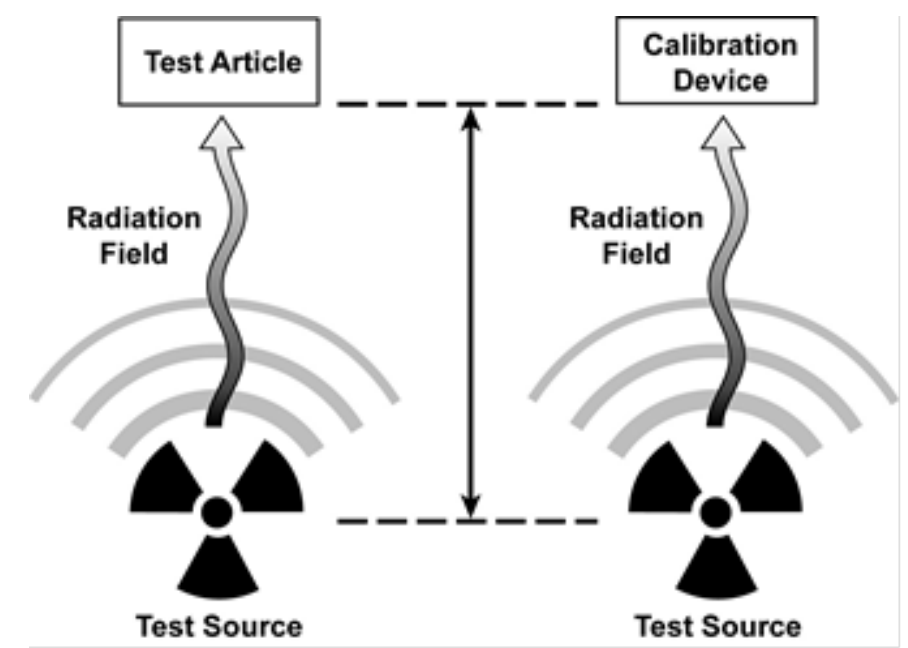

Figure 1: Test setup for exposure rate measurements

The instrument readings need to be corrected, using the instrument energy response function, for the gamma-ray energies being measured. The energy response function used for these corrections may be provided in the calibration certificated provided by the instrument manufacturer or by calibration measurements (see Appendix A).

When testing multiple radiation detection devices, the exposure rate must be measured at the location of each EUT to ensure the test field meets the requirements.

It is recommended to perform the exposure rate measurements at a distance where the exposure rate value is larger than $100 \mu \mathrm{R} / \mathrm{h}$ in order to reduce the uncertainty of the measurement. If a lower radiation field is needed to test the EUT and if the source is a point source, the inverse square law $\left(1 / \mathrm{r}^{2}\right)$ may be used to determine the required testing distance (depending on the scatter contribution to the measured value). The radiation field at the EUT should be verified using a calibrated device. An integrating dose device will work best for low radiation fields.

\subsubsection{Fluence rate measurement}

Fluence rate is the number of photons per unit area per seconds for a given geometry (ICRU Report 60). It can be determined for an energy spectrum of interest or for a given gamma-ray energy. Fluence rate measurements should be performed using a calibrated high purity 
germanium (HPGe) detector for a known geometry (for example, point sources at some distance) using traceable sources.

Measurements should account for background. This can be done by measuring background and subtracting the number of photons counted within the energy(s) of interest from the source measured value to provide a net fluence rate. The uncertainty in the net result can be minimized by maximizing the length of the background measurement.

The full-energy peak efficiency of the HPGe detector at a fixed measurement distance must be determined (see Appendix B). This distance should be the source-to-EUT distance. The measured values should be fitted with an appropriate function (for example, interpolation from different radionuclides and energy ranges, polynomial fitting in the log-log scale, or from Monte Carlo code and simulations) in order to determine the efficiency as a function of energy for the energy range of interest. The fitting function used should be documented.

The fluence rate measurements need be performed at the same source-to-detector distance as that used to determine the full energy peak efficiency of the HPGe detector to reduce the uncertainty in the measurements. If this is not possible, the inverse square law may be used to determine the source fluence rate and required testing distance (if applicable, see Appendix B).

Measurements should account for differences in source encapsulation if the encapsulation of the sources used to determine the full energy peak efficiency of the HPGe detector is different from the source for which the fluence rate is being determined.

Measure and correct the data for dead-time, if the HPGe detection system does not do this automatically, see Appendix B.

\subsubsection{Establish exposure rate/fluence rate uncertainties}

The following items need to be considered when determining the uncertainty of a measured exposure rate and/or fluence rate:

- calibration (energy and efficiency) uncertainty of measurement device,

- number of replicate measurements,

- uncertainty of background measurement,

- corrections for presence of impurities,

- uncertainty of source-to-detector distance measurement (including the use of the inverse square law correction, if applied),

- energy response of the instrument (energy response function or full-energy peak efficiency fit).

The following items need to be considered when determining the uncertainty of a calculated exposure rate and/or fluence rate:

- uncertainty of source activity,

- source encapsulation dimensions and type,

- uncertainties in the nuclear data (half-life, emission probabilities, photon energies),

- uncertainty in the conversion and correction factors,

- modeling uncertainties (if applicable). 
Refer to IEC Technical Report TR62461 and to the GUM 1995 for further information on establishing measurement uncertainties.

\subsubsection{Establish a background monitoring frequency}

The testing organizations need to be aware that background fluctuations, at the relatively low exposure rates used in some tests, can unduly influence test results. The background needs to be appropriately monitored to ensure that it remains within the standard test conditions.

Changes in background radiation (for example, due to changes in weather such as rain) can impact instrument testing by affecting the accuracy of a measurement or internal calculation of the alarm threshold performed by the EUT. Background should be, if at all possible, continually (every 30 seconds) data logged to allow verification of standards-based requirements as well as indicate whether or not any adverse indications during testing were a result of a change in background. Since data logging infers an electronic file, this file should be saved/maintained as part of the record.

The background measurement should be obtained using the same measurement process as specified for the radiation field measurement (for example, exposure rate and dose equivalent rate).

Some tests, such as false alarm tests, may require data collection over many hours, during which time the background may vary. Such variations are acceptable as long as they remain within the background radiation bounds specified in the standard.

Some radiation detection systems rely upon continuous measurements of certain portions of the radiation background (i.e., ${ }^{40} \mathrm{~K}$ photons) to stabilize the gain of the gamma-ray detection system. Such stabilization processes may fail to function correctly if the test environment (for example, environmental chamber) contains only low levels of ${ }^{40} \mathrm{~K}$, for example. For those specific test environments, it is recommended that additional material such as road salt be located near the test to elevate the background for that specific energy. The additional material should remain in the same location relative to the EUT for the duration of the test.

\subsection{Sources}

\subsubsection{Traceability}

Radiological tests require to use sources that are traceable to a national standard (for example, NIST, PTB, NPL). Sources can be purchased with certificates of traceability, or traceability may be established through a transfer standard. Sources can also be sent to accredited facilities or national metrology institutes for calibration of emission rate.

When traceable sources are not available (e.g., medical, SNM), it is recommended to use a calibrated HPGe detector to determine the source activity or emission rate. The efficiency calibration of the HPGe detector should be obtained using traceable sources, all sources used to perform the efficiency calibration should have the same encapsulation. If the source encapsulations are different, corrections should be applied to account for the differences. 
Climatic, mechanical, and electromagnetic tests do not require the use of a traceable source.

Sources are characterized by following parameters:

- Source activity value: value provided by the source certificate or obtained by HPGe detector measurements for gamma sources or neutron emission calibration.

- Uncertainty of the activity value: value provided by the source certificate or obtained by HPGe detector measurements for gamma sources or neutron emission calibration.

- Tolerance limit of the source activity: is the activity value range over which the source can be used for testing. Standards allow for different tolerance ranges such as $\pm 20 \%$, ( $0 \%$, $+10 \%),(0 \%$, $+20 \%)$, etc.

\subsubsection{Source housing or encapsulation - Gamma sources}

Sources may be encapsulated by different types of materials and material thicknesses. Some standards specify the source activity for a given type of encapsulation. Depending on the radiation source and its encapsulation (for example, length to diameter ratio of a cylindrical source housing), significant anisotropy in both fluence rate and energy distribution is possible. Verification of the emission rate is necessary when using sources that are encapsulated by materials other than that defined in the standards.

\subsubsection{Source use life - Gamma sources}

Standards require to use different radionuclides for testing different types of instruments. Many of these radionuclides, such as medical sources, have very short half-lives. Source activity or exposure rate should be measured or calculated at a frequency commensurate with the half-life of the source and the tolerance and uncertainties allowed by the standard. Additionally, the time for all the steps required to prepare the source for use (receiving, any necessary repackaging and permitting) should be accounted for.

Figure 2 below describes the relationship between the maximum allowable tolerance and the corresponding minimum frequency (as a function of half-life, $T_{1 / 2}$ ) at which an adjustment (e.g. in the source-to-EUT distance) is required. For example, if a tolerance of $\pm 10 \%$ is specified, adjustments should be made at time intervals no longer than $0.15 * T_{1 / 2}$. 


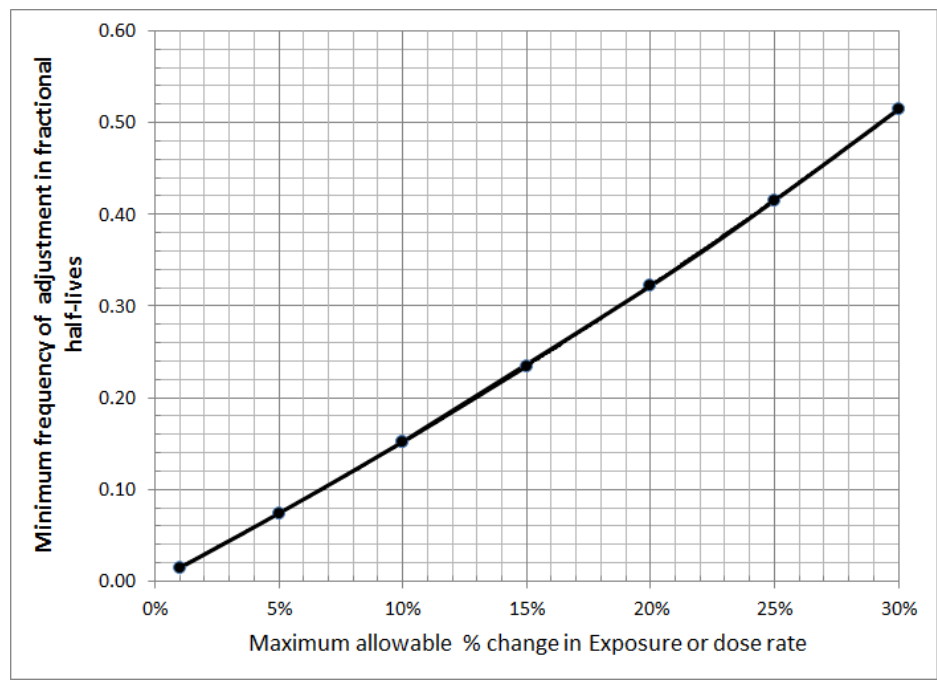

Figure 2: Relationship between minimum allowable tolerance and minimum frequency of adjustment.

The use of old sources at closer distances can create unexpected problems (for example, a larger detector may not be fully exposed to the radiation field). If the distance between the source and the EUT is reduced, care needs to be taken with larger EUTs to ensure that the entire system is still being exposed uniformly to the source.

In addition, some sources may contain long-lived impurities that become more dominant as the main radionuclide decays. This may lead to erroneous test results. Care should be taken by measuring sources to identify potential impurities and scatter peaks with an HPGe detector.

Multiple sources of the same radionuclide may be used to obtain the required exposure rate or dose equivalent rate. Care should be taken as not to produce an extended source when multiple sources are used, this will depend on the size of the detector under test, and that the sources do not shield one another. If several sources are used, a source holder should be used to ensure that the sources configuration is the same for all measurements.

\subsubsection{Neutron Sources}

The typically specified neutron source for alarm verification is ${ }^{252} \mathrm{Cf}$ with a half-life of 2.645 years.

Neutron sources are typically specified in test procedures as "moderated" and "unmoderated" or "bare". Moderated neutron sources are encased in a material such as polyethylene that moderates the neutron spectrum and affects fluence rate. Unmoderated sources are sealed sources, but the outer casing materials do not serve as a moderator (e.g., outer casing made out of steel). Moderated sources generally produce fields that are easier to detect due to the moderating influence of the surrounding material and the energy response function of the EUT. Standards normally specify high-density polyethylene as the moderating material. 


\subsubsection{General properties of a californium source}

A californium source activity may be quoted in three different ways: in $\mathrm{Bq}$ (or $\mu \mathrm{Ci})^{1}$, in micrograms $(\mu \mathrm{g})$ or in neutron emission rate units (neutrons/s in $4 \pi$ ).

When californium source activity is quoted in $\mu \mathrm{Ci}$ (or $\mathrm{Bq}$ ) it includes all disintegrations that produce alpha particles or neutrons. The relationship between ${ }^{252} \mathrm{Cf}$ activity units is as follows: ${ }^{252} \mathrm{Cf}$ emits $2.314 \times 10^{6} \mathrm{~s}^{-1} \mu \mathrm{g}^{-1}$, its specific activity is $19.832 \mathrm{MBq} / \mu \mathrm{g}$ (or $536 \mu \mathrm{Ci} / \mu \mathrm{g}$ ) and the neutron yield is $0.116 \mathrm{~s}^{-1} \mathrm{~Bq}^{-1}$ (or $1 \mu \mathrm{Ci}$ of ${ }^{252} \mathrm{Cf}$ emits $4316 \mathrm{~s}^{-1}$ ).

The neutron dose equivalent rate from $1 \mu \mathrm{g}$ of ${ }^{252} \mathrm{Cf}$ at $1 \mathrm{~m}$ without any shielding is $25.5 \mu \mathrm{Sv} / \mathrm{h}$ $(2.55 \mathrm{mrem} / \mathrm{h})$. The gamma rays contribute another $1.4 \mu \mathrm{Sv} / \mathrm{h}(0.14 \mathrm{mrem} / \mathrm{h})$. The dose equivalent rates (and emission rates) may slightly vary among different ${ }^{252} \mathrm{Cf}$ sources depending on their age, isotopic composition and encapsulation. In some standards, steel and lead shielding is used to reduce the contribution from the gamma-rays.

\subsubsection{Decay}

${ }^{252} \mathrm{Cf}$ sources should be recalibrated every five years. ${ }^{252} \mathrm{Cf}$ source emission rate needs to be corrected for radioactive decay on a day-to-day basis (ISO 8259). ${ }^{252} \mathrm{Cf}$ sources older than 15 years should not be used without recalibration due to the presence of longer-lived impurities.

Multiple ${ }^{252} \mathrm{Cf}$ sources can be combined to achieve the required emission rate. Due to the $\pm 20 \%$ tolerance limit on the neutron emission rate specified in the standards, a single ${ }^{252} \mathrm{Cf}$ source used for neutron standards-based testing will have a maximum usable life of about 1.5 years.

Neutron scatter should be considered and minimized. The air attenuation (air out scatter) and air in scatter of neutrons increases approximately linearly with the source-to-detector distance. The distance above concrete floors (and from concrete walls) should also be maximized. The neutron source and the EUT should both be positioned at least $1 \mathrm{~m}$ above a concrete floor.

Support structures should be light with little or no hydrogenous materials (e.g., aluminum). For all scatter contributions, the spectral and angular distribution is different from that of the original source spectrum. Therefore, the relative contribution of the scattered neutrons to the reading of the device is dependent upon the energy and angular response of the particular device. Avoid use of any organic materials (for example, polyethylene (Poly), polymethyl methacrylate (PMMA)) to support the ${ }^{252} \mathrm{Cf}$ source or EUT unless the test specifically requires the use of a phantom.

Consideration of neutron scatter is especially of concern when the ${ }^{252} \mathrm{Cf}$ source is unmoderated. When used in this fashion, the source of thermal neutrons upon which most instruments rely for detection, is not the ${ }^{252} \mathrm{Cf}$ source per se but the neutrons that have undergone subsequent energy-loss collisions within the test facility (e.g. concrete floors and walls). If the EUT is not surrounded by a hydrogenous moderator (e.g. polyethylene) or supported on a PMMA

${ }^{1}$ NIST does not endorse the use of non-SI units. This paper uses non-SI units because it addresses the requirements listed in the ANSI/IEEE published standards. 
phantom, the thermalized room-return neutrons are most likely to be detected by the EUT. A detector that is surrounded by a moderator or supported on a phantom is less influenced by room-return neutrons. In order to ensure that the ${ }^{252} \mathrm{Cf}$ source is the primary source term, maximize the distance to any scattering surface - particularly hydrogenous materials. Be aware also that, even though a concrete wall might be several meters away, scatter from the walls may be a significant source term if its surface area is large (i.e., the angle subtended by the wall is large).

\subsubsection{Radionuclide identification measurements - impurities}

For sources used to test radionuclide identification capabilities, measure the energy spectrum of the radiation source using a high-resolution detector in order to ensure that impurities in the source do not affect the identification results for the radionuclide of interest (for example, measure ${ }^{241} \mathrm{Am}$ content in WGPu source, contaminants in a medical radionuclide source). A high resolution and high statistics spectrum should be acquired for all sources used for testing to determine potential impurities, scatter peaks and radionuclide composition.

Reduce the emission of the source impurities if needed by shielding or replacement of the source. If shielding will not eliminate the impurity, or the photon energy of the impurity is greater than or equal to the target radionuclide energy, the source should be replaced. If a replacement source is unavailable, the impurities should be documented to ensure proper analysis of test results. The list of allowed identifiable radionuclides needs to include all impurities identified in the source spectrum.

\subsection{Coefficient of variation}

The coefficient of variation (COV) provides a description of the dispersion of a series of measurements. In the standards, COV plays a role when comparing the mean of several sets of measurements obtained from a radioactive source when the EUT is subjected to different environmental, mechanical, and electromagnetic influence quantities. The COV limit helps to ensure that a significant change in the instrument's performance due to an influence quantity is identified.

When determining a COV, the exposure rate needs to be high enough such that the COV is within the specified limit. If the COV is greater than the required limit, and cannot be reduced by increasing the radiation field, increase the number of readings. The number of pre-test readings should always equal the number of post-test readings. When collecting individual readings, one should be cognizant of the integration time constant to ensure the individual readings are truly independent.

Exposure to the influence quantities can impact both the average and variation (standard deviation) of the EUT readings. Therefore, both changes in the readings as well as changes in the variability of the readings should be part of the test documentation.

For additional information regarding COV and other statistical attributes, a good reference is the NIST/SEMATECH e-Handbook of Statistical Methods, see Appendix E. 


\section{Radiological tests}

\subsection{Gamma Set-up}

Source ranges and configurations are specified within the standard being tested, though there may be ambiguities about the exact setup conditions. Because test results can be very dependent on the source configuration, ambiguities should be clarified with the client prior to the beginning of testing. Ambiguities should be clarified through the use of test plans.

For tests requiring an EUT to be exposed to a high gamma-ray exposure rate that is uniform over the volume of detector (i.e., neutron indication in the presence of photons, overload, etc.), there are several methods for producing a uniform radiation field over the entire assembly to be tested; such as using a strong at a faraway distance or discrete point source covering a long distance.

For larger systems or subassemblies of instruments (i.e., PVT detector panels from a portal monitor) the required uniformity in the exposure rate over the detection assembly may not be realistically possible to obtain if using a single source, even when using a high activity source placed at a faraway distance. An array of lower activity sources may be used at a closer distance to produce the required uniform exposure rate over the detection assembly.

\subsection{EUT set-up}

There are many factors to consider when setting up EUT(s) for testing. Factors likely to be important in all testing to minimize uncertainty and to support repeatability and reproducibility of measurements are noted here. Distinctions are discussed, as applicable, for single EUTs versus multiple EUT testing, and static versus dynamic measurements.

It is helpful to understand how the EUT adjusts background values (sliding window average or other method), what happens when there is an occupancy or scan (background data collection suspended, or other method), and how long it takes for the EUT to return to confirmed natural background values once a source is removed (seconds or minute), this information needs to be obtained through documentation review or communications with the manufacturer. Each of these variables will influence how tests should be conducted.

Prior to testing, the reference point of the detector should be established and marked by using the manufacturer's instructions. If the reference point is not provided by the manufacturer, use the reference point defined in the standard or test instructions for the type of instrument being tested. If the standard or test instructions do not provide this information, use the effective vertical and horizontal center of the detector as the reference point. If bottom, middle, and top reference elevations (or testing heights) are specified in the test instructions, these should also be marked. Laser levels or other type of tools may be used to align the source center to the reference point of the EUT.

The relevant reference elevations and positions should be documented and used for all measurements (unless an intended exception is used) and documented. Prior to test planning, the reference point(s) of interest should be selected. Many tests are performed at the geometric mid-point of the component or detector panel or some derivative from that location. Detection equipment may be symmetric (e.g., gamma detector directly in front of the neutron detector) 
or asymmetric (e.g., gamma detector located beside the neutron detector). This should be considered during test planning.

Relative distances from the EUT to floors and walls, as well as the composition of the floor and walls, should be considered and assessed for potential impact to test conditions. For example, scatter and reflection is dependent on the setup of the EUT and test locations and is also dependent on source types (e.g., gamma versus neutron) and quantities. Careful consideration should be given to configuration modifications made midway through a test. Changes may require re-characterization of the fluence rate and spectrum at the measurement location and documentation of the changes with the reason.

When shielding is required to reduce the emission rate or the presence of impurities, low atomic number (low-Z) shields should be used to absorb beta particles and conversion electrons from radioactive sources. Low-Z materials (e.g., copper, aluminum) also minimize X-ray generation. To reduce the gamma-ray emissions produced by neutron sources, high- $Z$ materials such as lead, tungsten, or steel are typically used.

\subsubsection{Static measurements}

It is recommended to assess the following factors for static testing:

- Repeatable positioning and orientation of EUTs must be supported by using fixtures and jigs or markings for EUT placement. Fixtures and jigs should use materials and designs that minimize the potential for attenuation or scatter for the intended source measurements (e.g., use of aluminum or plastic for testing with gamma sources).

- If multiple instruments are tested together using the same source(s), instrument placements should consider factors that could impact the test results (e.g., self- shielding and radiation scatter due to the proximity of multiple instruments or room walls). The gap between each EUT should be large enough to prevent attenuation or scatter effects. It is recommended that simple measurements (such as a response check) be performed to ensure that the EUTs are not affected by adjacent instruments. Source geometry is also a factor (i.e., disks, plates, cylinders, spheres), the use of cylindrical or spherical sources allow to simultaneously test multiple EUT reducing the testing time and the potential impact of the test results. To minimize the impact in test results, the source-to-detector distance should also be considered.

\subsubsection{Dynamic measurements}

It is recommended to assess the following factors for dynamic testing:

- Isotropic sources should be used for dynamic testing. This ensures uniformity of the test field.

- EUTs setup should consider the choices for fixtures and EUTs carrier mechanisms for potential radiation scatter and attenuation when EUTs are moved and sources are stationary. 


\subsubsection{Angles}

When testing EUTs for angular dependency, setup should consider, in addition to the previously discussed factors, using one of the following methods as appropriate:

- A reference template with test angles marked to provide repeatable placement of different EUTs from test to test. Templates should have mounting and fixtures or markings for repeatable placements to minimize the possibility of changing distances or angles unintentionally as EUTs are moved to different positions.

- A manual or motorized rotational table with angles controlled by a handle or stepper motor.

- A placard in a photograph to document the EUT configuration and test angle.

\section{3. $\quad$ Source Set-up}

When the test specifies a quantified radiation field and multiple instruments are tested simultaneously (for example, arranged in an arc about a single source), the radiation field needs to be verified at the reference point for each EUT being tested.

When testing multiple EUTs, the EUTs should be physically arranged so each EUT is exposed to the same radiation field at each point of the test. Greater care is needed when performing dynamic testing (i.e., radiation field changes during a test) to ensure each EUT is exposed to the same dynamic radiation field for the duration of the test.

Some tests require multiple trials with the radiation field reduced to background between trials. For EUTs that adjust background rates over time (e.g., background values collected between occupancies to establish a running average), the presence of a source, even at some distance from an EUT, may affect the background determined by the EUT. This can produce a creeping background effect that impacts the performance of the EUT. Thus, removal of sources from the area or use of shielding methods between trials is recommended and may be essential to obtain valid test results. Background measurements, including gamma-ray spectra, should be performed when the sources are placed at the furthest distance from the EUT to verify that the strength and spectra of the radiation field produced by the sources at the EUT location is a small increase to the natural background (e.g., no more than a $10 \%$ increase in the exposure rate readings, no more than a 3-sigma increase in the count rate readings, place the sources at a distance of at least $5 \mathrm{~m}$ from the EUT).

\subsection{Medicals/Short-Lived Radionuclides}

Medical radionuclides have short half-lives. This can be challenging for tests that span many hours, requiring correction for source strength over the measurement period. It is recommended to establish a measurement schedule to ensure the source activity meets the requirements.

Medical radionuclides often emit low-energy photons that are more prone to scatter than higher energy photons. Greater care should be taken when working with medical radionuclides to account for (or minimize) scatter from floors, walls, and test fixtures. Low- $Z$ material (for example, aluminum, PMMA) EUT and source supports should be considered to reduce scatter. 


\subsection{Use of Phantoms}

Phantoms are often used during testing to simulate the effects of the human body on the EUT performance for those EUTs that are typically body-worn. The phantom provides scattering, reflection, and moderation effects similar to a human. Some EUTs may be designed to only perform correctly when next to a person (or phantom). Geometry of EUT placement becomes significant for such EUTs, and EUTs should be centered on the phantom. Multiple EUTs should not be tested simultaneously on the same phantom. Standards that require the use of phantoms typically specify the size, shape, and composition of the phantom. If the standard does not specify a phantom, a phantom that meets the specifications of ANSI N13.11 (current revision) should be used.

\subsection{Alarms and Indications}

Radiation detection systems typically use both audio and visual indications to communicate alarms, system alerts, system notifications, and system errors, among others. Not all equipment suppliers use the terminology consistently. Not all end users expect the same outputs. The EUT may also have unique logic associated with adjudicating the off-normal conditions. Understanding and documenting the terminology applicable to each system, the logical hierarchy, the mode of communication, the expected system response, and required operator adjudication actions, are critical for a good test design and execution.

Radiation alarms are generated when a predetermined radiation level is exceeded, specific radionuclides are identified, or signature characteristics meet predetermined criteria. Alarms can be based on exceeding a set activity or exposure rate level above background, a change in count rate, or the identification of radionuclides of interest, etc. depending on the instrument type. For spectrometric systems, the presence of NORM may or may not be communicated as an alarm depending on customer- or site-specific CONOPS or manufacturer settings. Alarm indications may or may not provide information on the radiation type and source (e.g., gammaray, neutron, alpha, beta, source identification).

System alerts typically communicate changes in the system status that may affect performance. Examples include switching to backup battery power when main power is cut off, or a degraded performance condition. System errors are sometimes defined to indicate when certain components are degraded or not functional such as loss of communications or other operations critical to system function.

The EUT may also have interlocks (hardware and software) and decision logic that locks the system status until an action is performed by the operator. These interlocks can affect test conduct. For example, an EUT may or may not be able to process other information or alarms until current alarms are acknowledged. This could be the case during a false alarm test.

Alarm indications may also be component-specific and can be indicated in several different ways: vibration, audible tone, voice notification, lights turning on, menu displayed codes, user interface icons, etc. For example, an alarm indication on a simplified remote user interface may flash yellow and beep once per second. This same alarm may provide additional details on the supervisor computer interface. Test design should be based on understanding both capabilities. 


\subsection{EUT Communication and File Creation}

If testing requires the use of the EUT response information saved in a data file, the EUT communication and file data format should be checked before the start of the test to ensure that it is produced, transmitted and readable by adequate tools.

\section{Acknowledgments}

The author will like to acknowledge the contributions to this document from Radoslav Radev from Lawrence Livermore National Laboratory, Tom McLean from Los Alamos National Laboratory, Dennis Leber from the National Institute of Standards and Technology, Nathan Wood and David West from Oak Ridge National Laboratory, Al Goodwyn and Charles Lewis from Savannah River National Laboratory.

\section{References}

[1] Wilkinson JP (1990) Nonlinear resonant circuit devices. United States Patent 3624 125.

[2] R. Radev and T. McLean. Neutron Sources for Standard-Based Testing. LLNL TR664160, November 2014.

[3] International Electrotechnical Commission (IEC) Technical Report 62461 Radiation Protection Instrumentation - Determination of Uncertainty in Measurement, IEC/TR 62461.

[4] ISO 8259, Reference neutron radiations - Part 3: Calibration of area and personal dosimeters and determination of their response as a function of neutron energy and angle of incidence.

[5] ISO 4037-3, X and gamma reference radiation for calibrating dosemeters and doserate meters and for determining their response as a function of photon energy -Part 3: Calibration of area and personal dosemeters and the measurement of their response as a function of energy and angle of incidence.

[6] IEC TR 62461:2015 Radiation protection instrumentation - Determination of uncertainty in measurement.

[7] ICRU Report 57, Conversion Coefficients for use in Radiological Protection against External Radiation. Issued August 1, 1998.

[8] ICRU Report 60, Fundamental quantities and units for ionizing radiation. Journal of the International Commission on Radiation Units and Measurements.

[9] IEC 62706, Radiation protection instrumentation - Recommended climatic, electromagnetic and mechanical performance requirements and methods of tests.

[10] GUM 1995, JCGM 100:2008. Evaluation of measurement data - Guide to the expression of uncertainty in measurement. 


\section{Appendix A: Exposure and ambient dose equivalent rate calculations}

\section{A.1 Calculation of exposure rate}

In order to have a consistent way to determine exposure rate, $\dot{X}$, among user of this guide, the following method is used. There might be different and perhaps slightly better methods to perform these determinations, but the most critical issue to address is the reproducibility and consistency across all the testing laboratories in how the determination of the radiation field is made. Due to the low exposure rates (i.e., $20 \mu \mathrm{R} / \mathrm{h}, 10 \mu \mathrm{R} / \mathrm{h}$ or $5 \mu \mathrm{R} / \mathrm{h}$ above background) required to perform some of the tests, it would not be possible to make accurate measurements with the uncertainty required by many standards of $\pm 20 \%(k=1)$.

The proposed method assumes a point source in air, and it does not account for buildup in air. The cut-off energy, $\delta$, used for the calculations is $40 \mathrm{keV}$, and for practical purposes all photon emissions with a probability larger than $0.5 \%$ are included in the calculation.

For the point source in vacuum, the fluence rate $\dot{\Phi}_{i}$ of photons with energy $E_{i}$ at a radial distance $r$ is simply $A P_{i} /\left(4 \pi r^{2}\right)$, where $A$ is the source activity, and $P_{i}$ is the probability per disintegration that a photon of energy $E_{i}$ is emitted. Assuming charged-particle equilibrium, the air-kerma rate $\dot{K}_{i}$ from photons of energy $E_{i}$ is then $\dot{K}_{i}=\dot{\Phi}_{\mathrm{i}} E_{\mathrm{i}} \frac{\mu_{\mathrm{tr}}\left(E_{i}\right)}{\rho_{\text {air }}}$, where $\frac{\mu_{t r}\left(E_{i}\right)}{\rho_{\text {air }}}$ is the mass energy-transfer coefficient for air [Ref. A.1]. In general, for a point source in vacuum, emitting more than one energy photon the air kerma rate is obtained by summing over all photon energies as follows:

$$
\dot{K}_{\delta}=\sum_{i} \frac{A P_{i} E_{i}}{4 \pi r^{2}} \frac{\mu_{t r}\left(E_{i}\right)}{\rho_{\text {air }}}
$$

where $\delta$ denotes the minimum photon energy included.

Now consider the point source surrounded by spherical shell(s) of encapsulating material in an infinite air medium. Each encapsulation material surrounding the source will have a thickness $z_{j}$ and a density $\rho_{j}$. The attenuation of the photon beam from any material surrounding the source and the column of air between the source and the point of detection can be accounted for by using the following estimate of the air-kerma rate at a radial distance $r$ :

$$
\dot{K}_{\delta}=\frac{A}{4 \pi r^{2}} \sum_{i} P_{i} E_{i} \frac{\mu_{t r}\left(E_{i}\right)}{\rho_{\text {air }}} \exp \left[-\sum_{j} \frac{\mu_{j}\left(E_{i}\right)}{\rho_{j}} \rho_{j} z_{j}\right] \exp \left[-\frac{\mu_{\text {air }}\left(E_{i}\right)}{\rho_{\text {air }}} \rho_{\text {air }} r\right] \text {, }
$$


where $\mu_{j} / \rho_{j}$ the mass attenuation coefficient for the encapsulating-layer material of thickness $z_{j}$ and a density $\rho_{j}$, and $\mu_{\text {air } / / \rho_{\text {air }}}$ is that for air. Note that in Equation A.2 there are two exponentials. The first one accounts for the attenuation of all the materials surrounding the source while the second exponential accounts for the attenuation of the air column.

The relationship between the radiation quantities of exposure $X$ (units of $\mathrm{R}$ ) and air-kerma $K$ (units of Gy) is given by

$$
K=X\left(2.58 \times 10^{-4}\right)\left(\frac{W}{e}\right)\left(\frac{1}{1-g}\right)
$$

where W/e is the mean energy expended in dry air by electrons per ion pair formed (equal to $33.97 \mathrm{~J} / \mathrm{C}$ ) [5], and $g$ is the mean fraction of the initial kinetic energy of secondary electrons liberated by photons that are lost through radioactive processes in air. The SI unit of exposure is the coulomb per kilogram $(\mathrm{C} / \mathrm{kg})$; the special unit of exposure, the roentgen $(\mathrm{R})$, is equal to exactly $2.58 \times 10^{-4} \mathrm{C} / \mathrm{kg}$.

$$
\mu_{e n}\left(E_{i}\right)=(1-g) \mu_{t r}\left(E_{i}\right)
$$

where $\mu_{e n}\left(E_{i}\right)$ is the mass energy-absorption in air; the values are listed in Table A.2.

From Equations A.2, A.3 and A.4 an expression for the exposure rate, $\dot{X}$, can be easily derived for the practical case of an encapsulated source in air as

$$
\dot{X}_{\delta}=\frac{114.1 A}{4 \pi r^{2}} \sum_{i} P_{i} E_{i} \frac{\mu_{e n}\left(E_{i}\right)}{\rho_{\text {air }}} \exp \left[-\sum_{j} \frac{\mu_{j}\left(E_{i}\right)}{\rho_{j}} z_{j} \rho_{j}\right] \exp \left[-\frac{\mu_{\text {air }}\left(E_{i}\right)}{\rho_{\text {air }}} r \rho_{\text {air }}\right] \text {, }
$$

In order to ensure that all testing laboratories obtain a consistent calculated value of the ambient dose equivalent rate, the different coefficients and values for the different quantities used in the equations above shall be taken from the following references:

- $\quad \mu_{j} / \rho_{j}$ and $\rho_{j}$ are obtained from the $X C O M$ database, see reference [Ref. A.2].

- $\quad P_{i}$ is obtained from reference [Ref A.3]; if a given radionuclide is not listed [Ref. A.3], then reference [Ref. A.4] is used. For convenience, due to the long decay chain, the values for the probabilities per disintegration $(P)$ for ${ }^{232} \mathrm{Th}$ and ${ }^{226} \mathrm{Ra}$ (in equilibrium) are listed here in Table A.1.

- The $\mu_{\mathrm{en} /} \rho_{\text {air }}$ and $\mu_{\text {air/ }} \rho_{\text {air }}$ values are given here in Table A.2.

- The density of air is $\rho_{\text {air }}=0.0012 \mathrm{~g} / \mathrm{cm}^{3}$.

- The cut-off energy, $\delta$, used for the calculations is $40 \mathrm{keV}$.

- All photon emissions with a probability larger than $0.5 \%$ need to be included in the calculation.

This method assumes that the sources used have small or negligible self-attenuation. This means that the dimensions and/or density of the source active material are such that the 
attenuation within the source is negligible. Appropriate corrections to Equation A.5 need to be applied to account for source self-attenuation for the case of large and/or dense sources.

Table A.1: Probabilities per disintegration for ${ }^{232} \mathrm{Th}$ and ${ }^{226} \mathrm{Ra}$ (in equilibrium) as a function of photon energy

\begin{tabular}{|c|c|c|c|}
\hline \multicolumn{2}{|c|}{${ }^{232} \mathrm{Th}$ (in equilibrium with progeny) } & \multicolumn{2}{|c|}{${ }^{226} \mathrm{Ra}$ (in equilibrium with progeny) } \\
\hline $\begin{array}{c}\text { Photon energy } \\
\text { keV }\end{array}$ & $P$ & $\begin{array}{c}\text { Photon energy } \\
\text { keV }\end{array}$ & $P$ \\
\hline 72.805 & 7.51E-03 & 46.539 & $4.312 \mathrm{E}-02$ \\
\hline 74.815 & $1.04 \mathrm{E}-01$ & 53.228 & $1.060 \mathrm{E}-02$ \\
\hline 74.969 & $1.26 \mathrm{E}-02$ & 74.816 & $6.26 \mathrm{E}-02$ \\
\hline 77.107 & $1.75 \mathrm{E}-01$ & 77.109 & $1.047 \mathrm{E}-01$ \\
\hline 84.373 & $1.22 \mathrm{E}-02$ & 79.293 & $7.12 \mathrm{E}-03$ \\
\hline 86.83 & 2.09E-02 & 87.344 & $3.59 \mathrm{E}-02$ \\
\hline 87.349 & 4.01E-02 & 89.784 & $6.70 \mathrm{E}-03$ \\
\hline 89.784 & $1.46 \mathrm{E}-02$ & 90.074 & $1.10 \mathrm{E}-02$ \\
\hline 89.957 & $1.96 \mathrm{E}-02$ & 186.211 & $3.555 \mathrm{E}-02$ \\
\hline 93.35 & 3.19E-02 & 241.997 & $7.268 \mathrm{E}-02$ \\
\hline 99.509 & $1.26 \mathrm{E}-02$ & 258.87 & $5.24 \mathrm{E}-03$ \\
\hline 105.604 & 7.40E-03 & 295.224 & $1.8414 \mathrm{E}-01$ \\
\hline 115.183 & $5.92 \mathrm{E}-03$ & 351.932 & $3.56 \mathrm{E}-01$ \\
\hline 129.065 & $2.42 \mathrm{E}-02$ & 609.312 & 4.549E-01 \\
\hline 153.977 & $7.22 \mathrm{E}-03$ & 665.453 & $1.53 \mathrm{E}-02$ \\
\hline 209.253 & 3.89E-02 & 768.356 & 4.892E-02 \\
\hline 238.632 & 4.33E-01 & 785.96 & $1.064 \mathrm{E}-02$ \\
\hline 240.986 & 4.10E-02 & 806.174 & $1.262 \mathrm{E}-02$ \\
\hline 270.245 & $3.46 \mathrm{E}-02$ & 839.04 & 5.87E-03 \\
\hline 277.351 & 2.27E-02 & 934.061 & $3.10 \mathrm{E}-02$ \\
\hline 300.087 & $3.28 \mathrm{E}-02$ & 1120.287 & $1.491 \mathrm{E}-01$ \\
\hline 328 & $2.95 \mathrm{E}-02$ & 1155.19 & $1.635 \mathrm{E}-02$ \\
\hline 338.32 & $1.13 \mathrm{E}-01$ & 1238.111 & $5.831 \mathrm{E}-02$ \\
\hline 409.462 & 1.92E-02 & 1280.96 & $1.435 \mathrm{E}-02$ \\
\hline 463.004 & 4.40E-02 & 1377.669 & $3.968 \mathrm{E}-02$ \\
\hline 510.77 & $8.12 \mathrm{E}-02$ & 1385.31 & $7.95 \mathrm{E}-03$ \\
\hline 562.5 & 8.70E-03 & 1401.5 & $1.33 \mathrm{E}-02$ \\
\hline 583.191 & 3.04E-01 & 1407.98 & $2.389 \mathrm{E}-02$ \\
\hline
\end{tabular}




\begin{tabular}{|c|c|c|c|}
\hline 726.863 & $6.20 \mathrm{E}-03$ & 1509.228 & $2.128 \mathrm{E}-02$ \\
\hline 727.33 & $6.58 \mathrm{E}-02$ & 1583.22 & 7.07E-03 \\
\hline 755.315 & 1.00E-02 & 1661.28 & $1.048 \mathrm{E}-02$ \\
\hline 763.13 & $6.52 \mathrm{E}-03$ & 1729.595 & $2.844 \mathrm{E}-02$ \\
\hline 772.291 & $1.49 \mathrm{E}-02$ & 1764.494 & $1.531 \mathrm{E}-01$ \\
\hline 794.947 & $4.25 \mathrm{E}-02$ & 1847.42 & $2.025 \mathrm{E}-02$ \\
\hline 830.486 & $5.40 \mathrm{E}-03$ & 2118.55 & $1.158 \mathrm{E}-02$ \\
\hline 835.71 & $1.61 \mathrm{E}-02$ & 2204.21 & $4.913 \mathrm{E}-02$ \\
\hline 840.377 & $9.10 \mathrm{E}-03$ & 2447.86 & $1.548 \mathrm{E}-02$ \\
\hline 860.564 & 4.46E-02 & & \\
\hline 904.19 & 7.70E-03 & & \\
\hline 911.204 & $2.58 \mathrm{E}-01$ & & \\
\hline 964.766 & 4.99E-02 & & \\
\hline 968.971 & $1.58 \mathrm{E}-01$ & & \\
\hline 1078.62 & $5.64 \mathrm{E}-03$ & & \\
\hline 1247.08 & $5.00 \mathrm{E}-03$ & & \\
\hline 1459.138 & 8.30E-03 & & \\
\hline 1495.93 & 8.60E-03 & & \\
\hline 1580.53 & $6.00 \mathrm{E}-03$ & & \\
\hline 1588.19 & $3.22 \mathrm{E}-02$ & & \\
\hline 1620.5 & $1.49 \mathrm{E}-02$ & & \\
\hline 1630.627 & $1.51 \mathrm{E}-02$ & & \\
\hline 2614.453 & $3.56 \mathrm{E}-01$ & & \\
\hline
\end{tabular}

Table A.2: Values of the mass energy-transfer, mass energy-absorption, and mass attenuation coefficients for

\begin{tabular}{|c|c|c|c|c|}
\hline \multicolumn{1}{c|}{$\begin{array}{c}\text { Photon Energy } \\
\text { MeV }\end{array}$} & $\begin{array}{c}\mu_{\mathrm{tr}} / \rho \\
\left(\mathrm{cm}^{2} / \mathrm{g}\right)\end{array}$ & $\begin{array}{c}\mu_{\mathrm{en}} / \rho \\
\left(\mathrm{cm}^{2} / \mathrm{g}\right)\end{array}$ & $\begin{array}{c}\mu / \rho \\
\left(\mathrm{cm}^{2} / \mathrm{g}\right)\end{array}$ \\
\hline $1.000 \mathrm{E}-03$ & $3.599 \mathrm{E}+03$ & $3.599 \mathrm{E}+03$ & $3.606 \mathrm{E}+03$ \\
\hline $1.500 \mathrm{E}-03$ & $1.188 \mathrm{E}+03$ & $1.188 \mathrm{E}+03$ & $1.191 \mathrm{E}+03$ \\
\hline $2.000 \mathrm{E}-03$ & $5.263 \mathrm{E}+02$ & $5.262 \mathrm{E}+02$ & $5.279 \mathrm{E}+02$ \\
\hline $3.000 \mathrm{E}-03$ & $1.615 \mathrm{E}+02$ & $1.614 \mathrm{E}+02$ & $1.625 \mathrm{E}+02$ \\
\hline $3.203 \mathrm{E}-03$ & $1.330 \mathrm{E}+02$ & $1.330 \mathrm{E}+02$ & $1.340 \mathrm{E}+02$ \\
\hline $3.203 \mathrm{E}-03$ & $1.460 \mathrm{E}+02$ & $1.460 \mathrm{E}+02$ & $1.485 \mathrm{E}+02$ \\
\hline $4.000 \mathrm{E}-03$ & $7.637 \mathrm{E}+01$ & $7.636 \mathrm{E}+01$ & $7.788 \mathrm{E}+01$ \\
\hline
\end{tabular}




\begin{tabular}{|c|c|c|c|}
\hline $5.000 \mathrm{E}-03$ & $3.932 E+01$ & $3.931 E+01$ & $4.027 \mathrm{E}+01$ \\
\hline $6.000 \mathrm{E}-03$ & $2.271 \mathrm{E}+01$ & $2.270 \mathrm{E}+01$ & $2.341 \mathrm{E}+01$ \\
\hline 8.000E-03 & $9.448 \mathrm{E}+00$ & $9.446 \mathrm{E}+00$ & $9.921 \mathrm{E}+00$ \\
\hline $1.000 \mathrm{E}-02$ & $4.743 E+00$ & $4.742 \mathrm{E}+00$ & $5.120 \mathrm{E}+00$ \\
\hline $1.500 \mathrm{E}-02$ & $1.334 \mathrm{E}+00$ & $1.334 \mathrm{E}+00$ & $1.614 \mathrm{E}+00$ \\
\hline $2.000 \mathrm{E}-02$ & $5.391 \mathrm{E}-01$ & $5.389 \mathrm{E}-01$ & 7.779E-01 \\
\hline 3.000E-02 & $1.538 \mathrm{E}-01$ & $1.537 \mathrm{E}-01$ & $3.538 \mathrm{E}-01$ \\
\hline 4.000E-02 & $6.836 \mathrm{E}-02$ & $6.833 \mathrm{E}-02$ & $2.485 \mathrm{E}-01$ \\
\hline $5.000 \mathrm{E}-02$ & 4.100E-02 & $4.098 \mathrm{E}-02$ & $2.080 \mathrm{E}-01$ \\
\hline $6.000 \mathrm{E}-02$ & $3.042 \mathrm{E}-02$ & $3.041 \mathrm{E}-02$ & $1.875 \mathrm{E}-01$ \\
\hline 8.000E-02 & $2.408 \mathrm{E}-02$ & $2.407 \mathrm{E}-02$ & $1.662 \mathrm{E}-01$ \\
\hline $1.000 \mathrm{E}-01$ & $2.326 \mathrm{E}-02$ & $2.325 \mathrm{E}-02$ & $1.541 \mathrm{E}-01$ \\
\hline $1.500 \mathrm{E}-01$ & 2.497E-02 & $2.496 \mathrm{E}-02$ & $1.356 \mathrm{E}-01$ \\
\hline $2.000 \mathrm{E}-01$ & $2.674 \mathrm{E}-02$ & $2.672 \mathrm{E}-02$ & $1.233 \mathrm{E}-01$ \\
\hline $3.000 \mathrm{E}-01$ & $2.875 \mathrm{E}-02$ & $2.872 \mathrm{E}-02$ & 1.067E-01 \\
\hline 4.000E-01 & $2.953 \mathrm{E}-02$ & $2.949 \mathrm{E}-02$ & $9.549 \mathrm{E}-02$ \\
\hline $5.000 \mathrm{E}-01$ & $2.971 \mathrm{E}-02$ & $2.966 \mathrm{E}-02$ & $8.712 \mathrm{E}-02$ \\
\hline $6.000 \mathrm{E}-01$ & $2.958 \mathrm{E}-02$ & $2.953 \mathrm{E}-02$ & 8.055E-02 \\
\hline $8.000 \mathrm{E}-01$ & $2.889 \mathrm{E}-02$ & $2.882 \mathrm{E}-02$ & 7.074E-02 \\
\hline $1.000 \mathrm{E}+00$ & 2.797E-02 & $2.789 \mathrm{E}-02$ & $6.358 \mathrm{E}-02$ \\
\hline $1.250 \mathrm{E}+00$ & $2.675 \mathrm{E}-02$ & $2.666 \mathrm{E}-02$ & 5.687E-02 \\
\hline $1.500 \mathrm{E}+00$ & 2.557E-02 & $2.547 \mathrm{E}-02$ & 5.175E-02 \\
\hline $2.000 \mathrm{E}+00$ & $2.359 \mathrm{E}-02$ & $2.345 \mathrm{E}-02$ & 4.447E-02 \\
\hline $3.000 \mathrm{E}+00$ & $2.076 \mathrm{E}-02$ & 2.057E-02 & $3.581 \mathrm{E}-02$ \\
\hline $4.000 \mathrm{E}+00$ & $1.894 \mathrm{E}-02$ & $1.870 \mathrm{E}-02$ & $3.079 \mathrm{E}-02$ \\
\hline $5.000 \mathrm{E}+00$ & $1.770 \mathrm{E}-02$ & $1.740 \mathrm{E}-02$ & $2.751 \mathrm{E}-02$ \\
\hline $6.000 \mathrm{E}+00$ & $1.683 \mathrm{E}-02$ & $1.647 \mathrm{E}-02$ & $2.522 \mathrm{E}-02$ \\
\hline $8.000 \mathrm{E}+00$ & $1.571 \mathrm{E}-02$ & $1.525 \mathrm{E}-02$ & $2.225 \mathrm{E}-02$ \\
\hline $1.000 \mathrm{E}+01$ & $1.506 \mathrm{E}-02$ & $1.450 \mathrm{E}-02$ & $2.045 \mathrm{E}-02$ \\
\hline $1.500 \mathrm{E}+01$ & $1.434 \mathrm{E}-02$ & $1.353 \mathrm{E}-02$ & $1.810 \mathrm{E}-02$ \\
\hline $2.000 \mathrm{E}+01$ & $1.415 \mathrm{E}-02$ & $1.311 \mathrm{E}-02$ & $1.705 \mathrm{E}-02$ \\
\hline
\end{tabular}

\section{A.2 Ambient dose equivalent rate calculation}

In order to have a consistent way to determine the ambient dose equivalent rate, $\dot{H}^{*}(10)$, among users, the following method is used. There might be different and perhaps slightly better 
methods to perform these determinations, but the most critical issue to address the reproducibility and consistency across all the testing laboratories in how the determinations of the radiation fields are made. Due to the low ambient dose equivalent rates (i.e., $0.05 \mu \mathrm{Sv} \cdot \mathrm{h}^{-1}$ above background) required to perform some of the tests, it would not be possible to make accurate measurements with the uncertainty required by the many standards of $\pm 20 \%(k=1)$.

The proposed method assumes a point source in air, and it does not account for buildup in air. The cut-off energy, $\delta$, used for the calculations is $40 \mathrm{keV}$, and for practical purposes all photon emissions with a probability larger than $0.5 \%$ need to be included in the calculation.

For the point source in vacuum, the fluence rate $\dot{\Phi}_{i}$ of photons with energy $E_{i}$ at a radial distance $r$ is simply $A P_{i} /\left(4 \pi r^{2}\right)$, where $A$ is the source activity, and $P_{i}$ is the probability per disintegration that a photon of energy $E_{i}$ is emitted. Assuming charged-particle equilibrium, the air-kerma rate $\dot{K}_{i}$ from photons of energy $E_{i}$ is then $\dot{K}_{i}=\dot{\Phi}_{\mathrm{i}} E_{\mathrm{i}} \frac{\mu_{\mathrm{tr}}\left(E_{i}\right)}{\rho_{\text {air }}}$, where $\frac{\mu_{t r}\left(E_{i}\right)}{\rho_{\text {air }}}$ is the mass energy-transfer coefficient for air [Ref. A.1]. In general, for a point source in vacuum, emitting more than one energy photon the air kerma rate is obtained by summing over all photon energies as follows:

$$
\dot{K}_{\delta}=\sum_{i} \frac{A P_{i} E_{i}}{4 \pi r^{2}} \frac{\mu_{t r}\left(E_{i}\right)}{\rho_{\text {air }}}
$$

where $\delta$ denotes the minimum photon energy included.

Now consider the point source surrounded by spherical shell(s) of encapsulating material in an infinite air medium. Each encapsulation material surrounding the source will have a thickness $z_{j}$ and a density $\rho_{j}$. The attenuation of the photon beam from any material surrounding he source and the column of air between the source and the point of detection can be accounted for by using the following estimate of the air-kerma rate at a radial distance $r$ :

$$
\dot{K}_{\delta}=\frac{A}{4 \pi r^{2}} \sum_{i} P_{i} E_{i} \frac{\mu_{t r}\left(E_{i}\right)}{\rho_{\text {air }}} \exp \left[-\sum_{j} \frac{\mu_{j}\left(E_{i}\right)}{\rho_{j}} \rho_{j} z_{j}\right] \exp \left[-\frac{\mu_{\text {air }}\left(E_{i}\right)}{\rho_{\text {air }}} \rho_{\text {air }} r\right],
$$

where $\mu_{j} \rho_{j}$ the mass attenuation coefficient for the encapsulating-layer material of thickness $z_{j}$ and a density $\rho_{j}$, and $\mu_{\text {air } / / \rho_{\text {air }}}$ is that for air. Note that in Equation A.7 there are two exponentials. The first one accounts for the attenuation of all the materials surrounding the source while the second exponential accounts for the attenuation of the air column. From Equation A.7 an expression for the ambient dose equivalent rate, $\dot{H}^{*}(10)$, can be easily derived for the practical case of an encapsulated source in air as 


$$
\dot{H}^{*}(10)=\frac{A}{4 \pi r^{2}} \sum_{i} h_{K}^{*}(10)_{i} P_{i} E_{i} \frac{\mu_{t r}\left(E_{i}\right)}{\rho_{\text {air }}} \exp \left[-\sum_{j} \frac{\mu_{j}\left(E_{i}\right)}{\rho_{j}} z_{j} \rho_{j}\right] \exp \left[-\frac{\mu_{\text {air }}\left(E_{i}\right)}{\rho_{\text {air }}} r \rho_{\text {air }}\right]
$$

where $h_{\mathrm{K}}^{*}(10)$ is the conversion coefficient from air kerma to ambient dose equivalent for mono-energetic and parallel photon radiation, and the use of the cut-off energy $\delta$ is assumed.

In order to ensure that all testing laboratories obtain a consistent calculated value of the ambient dose equivalent rate, the different coefficients and values for the different quantities used in the equations above shall be taken from the following references:

- $\quad h_{\mathrm{K}}^{*}(10)$ values are taken from the ISO 4037-3:1999 standard. For convenience these values are also provided in this document in Table A.3.

- $\quad \mu_{j} \rho_{j}$ and $\rho_{j}$ are obtained from the XCOM database, see reference [Ref. A.2].

- $\quad P_{i}$ is obtained from reference [3]; if a given radionuclide is not listed [Ref. A.3], then reference [Ref. A.4] is used. For convenience, due to the long decay chain, the values for the probabilities per disintegration $(P)$ for ${ }^{232} \mathrm{Th}$ and ${ }^{226} \mathrm{Ra}$ (in equilibrium) are listed here in Table A.1.

- The $\mu_{\mathrm{tr} /} \rho_{\text {air }}$ and $\mu_{\text {air } /} \rho_{\text {air }}$ values are given here in Table A.2.

- The density of air is $\rho_{\text {air }}=0.0012 \mathrm{~g} / \mathrm{cm}^{3}$.

- The cut-off energy, $\delta$, used for the calculations is $40 \mathrm{keV}$.

- All photon emissions with a probability larger than $0.5 \%$ need to be included in the calculation.

This method assumes that the sources used have small or negligible self-attenuation. This means that the dimensions and/or density of the source active material are such that the attenuation within the source is negligible. Appropriate corrections to Equation A.8 need to be applied to account for source self-attenuation for the case of large and/or dense sources.

Table A.3: Conversion coefficient $h_{\mathrm{K}}^{*}(10)$ from air kerma, $K$, to ambient dose equivalent, $H^{*}(10)$, for mono-energetic and parallel photon beams

\begin{tabular}{|c|c|}
\hline $\begin{array}{c}\text { Photon energy } \\
\text { keV }\end{array}$ & $\begin{array}{c}h^{*}{ }(10) \\
\text { Sv/Gy }\end{array}$ \\
\hline 10 & 0.008 \\
\hline 15 & 0.26 \\
\hline 20 & 0.61 \\
\hline 30 & 1.10 \\
\hline 40 & 1.47 \\
\hline 50 & 1.67 \\
\hline 60 & 1.74 \\
\hline
\end{tabular}




\begin{tabular}{|c|c|}
\hline 80 & 1.72 \\
\hline 100 & 1.65 \\
\hline 150 & 1.49 \\
\hline 200 & 1.40 \\
\hline 300 & 1.31 \\
\hline 400 & 1.26 \\
\hline 500 & 1.23 \\
\hline 600 & 1.21 \\
\hline 800 & 1.19 \\
\hline 1000 & 1.17 \\
\hline 1500 & 1.15 \\
\hline 2000 & 1.14 \\
\hline 3000 & 1.13 \\
\hline 4000 & 1.12 \\
\hline 5000 & 1.11 \\
\hline 6000 & 1.11 \\
\hline 8000 & 1.11 \\
\hline 10000 & 1.10 \\
\hline
\end{tabular}

Table A.4: Probabilities per disintegration for ${ }^{232} \mathrm{Th}$ and ${ }^{226} \mathrm{Ra}$ (in equilibrium) as a function of photon energy

\begin{tabular}{|c|c|c|c|}
\hline \multicolumn{2}{|c|}{${ }^{232} \mathrm{Th}$ (in equilibrium with progeny) } & \multicolumn{2}{|c|}{${ }^{226} \mathrm{Ra}$ (in equilibrium with progeny) } \\
\hline $\begin{array}{c}\text { Photon energy } \\
\text { keV }\end{array}$ & $P$ & $\begin{array}{c}\text { Photon energy } \\
\text { keV }\end{array}$ & $P$ \\
\hline 72.805 & 7.51E-03 & 46.539 & 4.312E-02 \\
\hline 74.815 & 1.04E-01 & 53.228 & $1.060 \mathrm{E}-02$ \\
\hline 74.969 & $1.26 \mathrm{E}-02$ & 74.816 & $6.26 \mathrm{E}-02$ \\
\hline 77.107 & $1.75 \mathrm{E}-01$ & 77.109 & $1.047 \mathrm{E}-01$ \\
\hline 84.373 & $1.22 \mathrm{E}-02$ & 79.293 & 7.12E-03 \\
\hline 86.83 & 2.09E-02 & 87.344 & $3.59 \mathrm{E}-02$ \\
\hline 87.349 & $4.01 \mathrm{E}-02$ & 89.784 & $6.70 \mathrm{E}-03$ \\
\hline 89.784 & $1.46 \mathrm{E}-02$ & 90.074 & $1.10 \mathrm{E}-02$ \\
\hline 89.957 & $1.96 \mathrm{E}-02$ & 186.211 & $3.555 \mathrm{E}-02$ \\
\hline 93.35 & 3.19E-02 & 241.997 & $7.268 \mathrm{E}-02$ \\
\hline 99.509 & $1.26 \mathrm{E}-02$ & 258.87 & $5.24 \mathrm{E}-03$ \\
\hline
\end{tabular}




\begin{tabular}{|c|c|c|c|}
\hline 105.604 & 7.40E-03 & 295.224 & $1.8414 \mathrm{E}-01$ \\
\hline 115.183 & $5.92 \mathrm{E}-03$ & 351.932 & $3.56 \mathrm{E}-01$ \\
\hline 129.065 & $2.42 \mathrm{E}-02$ & 609.312 & 4.549E-01 \\
\hline 153.977 & 7.22E-03 & 665.453 & $1.53 \mathrm{E}-02$ \\
\hline 209.253 & $3.89 \mathrm{E}-02$ & 768.356 & $4.892 \mathrm{E}-02$ \\
\hline 238.632 & 4.33E-01 & 785.96 & $1.064 \mathrm{E}-02$ \\
\hline 240.986 & 4.10E-02 & 806.174 & $1.262 \mathrm{E}-02$ \\
\hline 270.245 & $3.46 \mathrm{E}-02$ & 839.04 & 5.87E-03 \\
\hline 277.351 & 2.27E-02 & 934.061 & $3.10 \mathrm{E}-02$ \\
\hline 300.087 & $3.28 \mathrm{E}-02$ & 1120.287 & $1.491 \mathrm{E}-01$ \\
\hline 328 & $2.95 \mathrm{E}-02$ & 1155.19 & $1.635 \mathrm{E}-02$ \\
\hline 338.32 & $1.13 \mathrm{E}-01$ & 1238.111 & $5.831 \mathrm{E}-02$ \\
\hline 409.462 & $1.92 \mathrm{E}-02$ & 1280.96 & $1.435 \mathrm{E}-02$ \\
\hline 463.004 & 4.40E-02 & 1377.669 & $3.968 \mathrm{E}-02$ \\
\hline 510.77 & $8.12 \mathrm{E}-02$ & 1385.31 & 7.95E-03 \\
\hline 562.5 & 8.70E-03 & 1401.5 & $1.33 \mathrm{E}-02$ \\
\hline 583.191 & $3.04 \mathrm{E}-01$ & 1407.98 & $2.389 \mathrm{E}-02$ \\
\hline 726.863 & $6.20 \mathrm{E}-03$ & 1509.228 & $2.128 \mathrm{E}-02$ \\
\hline 727.33 & $6.58 \mathrm{E}-02$ & 1583.22 & 7.07E-03 \\
\hline 755.315 & $1.00 \mathrm{E}-02$ & 1661.28 & $1.048 \mathrm{E}-02$ \\
\hline 763.13 & $6.52 \mathrm{E}-03$ & 1729.595 & $2.844 \mathrm{E}-02$ \\
\hline 772.291 & $1.49 \mathrm{E}-02$ & 1764.494 & $1.531 \mathrm{E}-01$ \\
\hline 794.947 & $4.25 \mathrm{E}-02$ & 1847.42 & $2.025 \mathrm{E}-02$ \\
\hline 830.486 & $5.40 \mathrm{E}-03$ & 2118.55 & $1.158 \mathrm{E}-02$ \\
\hline 835.71 & $1.61 \mathrm{E}-02$ & 2204.21 & $4.913 \mathrm{E}-02$ \\
\hline 840.377 & $9.10 \mathrm{E}-03$ & 2447.86 & $1.548 \mathrm{E}-02$ \\
\hline 860.564 & 4.46E-02 & & \\
\hline 904.19 & 7.70E-03 & & \\
\hline 911.204 & $2.58 \mathrm{E}-01$ & & \\
\hline 964.766 & 4.99E-02 & & \\
\hline 968.971 & $1.58 \mathrm{E}-01$ & & \\
\hline 1078.62 & $5.64 \mathrm{E}-03$ & & \\
\hline 1247.08 & $5.00 \mathrm{E}-03$ & & \\
\hline 1459.138 & 8.30E-03 & & \\
\hline 1495.93 & 8.60E-03 & & \\
\hline 1580.53 & $6.00 \mathrm{E}-03$ & & \\
\hline
\end{tabular}




\begin{tabular}{|r|l|l|l|}
\hline 1588.19 & $3.22 \mathrm{E}-02$ & & \\
\hline 1620.5 & $1.49 \mathrm{E}-02$ & & \\
\hline 1630.627 & $1.51 \mathrm{E}-02$ & & \\
\hline 2614.453 & $3.56 \mathrm{E}-01$ & & \\
\hline
\end{tabular}

Table A.5: Values of the mass energy-transfer and mass attenuation coefficients for air

\begin{tabular}{|c|c|c|}
\hline $\begin{array}{c}\text { Photon Energy } \\
\text { MeV }\end{array}$ & $\begin{array}{c}\mu_{\mathrm{tr}} / \rho \\
\mathrm{cm}^{2} / \mathrm{g}\end{array}$ & $\begin{array}{c}\mu / \rho \\
\mathrm{cm}^{2} / \mathrm{g}\end{array}$ \\
\hline $1.000 \mathrm{E}-03$ & $3.599 \mathrm{E}+03$ & $3.606 \mathrm{E}+03$ \\
\hline $1.500 \mathrm{E}-03$ & $1.188 \mathrm{E}+03$ & $1.191 \mathrm{E}+03$ \\
\hline $2.000 \mathrm{E}-03$ & $5.263 \mathrm{E}+02$ & $5.279 \mathrm{E}+02$ \\
\hline $3.000 \mathrm{E}-03$ & $1.615 \mathrm{E}+02$ & $1.625 \mathrm{E}+02$ \\
\hline $3.203 \mathrm{E}-03$ & $1.330 \mathrm{E}+02$ & $1.340 \mathrm{E}+02$ \\
\hline $3.203 \mathrm{E}-03$ & $1.460 \mathrm{E}+02$ & $1.485 \mathrm{E}+02$ \\
\hline $4.000 \mathrm{E}-03$ & $7.637 \mathrm{E}+01$ & $7.788 \mathrm{E}+01$ \\
\hline $5.000 \mathrm{E}-03$ & $3.932 \mathrm{E}+01$ & $4.027 \mathrm{E}+01$ \\
\hline $6.000 \mathrm{E}-03$ & $2.271 \mathrm{E}+01$ & $2.341 \mathrm{E}+01$ \\
\hline $8.000 \mathrm{E}-03$ & $9.448 \mathrm{E}+00$ & $9.921 \mathrm{E}+00$ \\
\hline $1.000 \mathrm{E}-02$ & $4.743 \mathrm{E}+00$ & $5.120 \mathrm{E}+00$ \\
\hline $1.500 \mathrm{E}-02$ & $1.334 \mathrm{E}+00$ & $1.614 \mathrm{E}+00$ \\
\hline $2.000 \mathrm{E}-02$ & $5.391 \mathrm{E}-01$ & $7.779 \mathrm{E}-01$ \\
\hline $3.000 \mathrm{E}-02$ & $1.538 \mathrm{E}-01$ & $3.538 \mathrm{E}-01$ \\
\hline $4.000 \mathrm{E}-02$ & $6.836 \mathrm{E}-02$ & $2.485 \mathrm{E}-01$ \\
\hline $5.000 \mathrm{E}-02$ & $4.100 \mathrm{E}-02$ & $2.080 \mathrm{E}-01$ \\
\hline $6.000 \mathrm{E}-02$ & $3.042 \mathrm{E}-02$ & $1.875 \mathrm{E}-01$ \\
\hline $8.000 \mathrm{E}-02$ & $2.408 \mathrm{E}-02$ & $1.662 \mathrm{E}-01$ \\
\hline $1.000 \mathrm{E}-01$ & $2.326 \mathrm{E}-02$ & $1.541 \mathrm{E}-01$ \\
\hline $1.500 \mathrm{E}-01$ & $2.497 \mathrm{E}-02$ & $1.356 \mathrm{E}-01$ \\
\hline $2.000 \mathrm{E}-01$ & $2.674 \mathrm{E}-02$ & $1.233 \mathrm{E}-01$ \\
\hline $3.000 \mathrm{E}-01$ & $2.875 \mathrm{E}-02$ & $1.067 \mathrm{E}-01$ \\
\hline $4.000 \mathrm{E}-01$ & $2.953 \mathrm{E}-02$ & $9.549 \mathrm{E}-02$ \\
\hline $5.000 \mathrm{E}-01$ & $2.971 \mathrm{E}-02$ & $8.712 \mathrm{E}-02$ \\
\hline
\end{tabular}




\begin{tabular}{|l|l|l|}
\hline $6.000 \mathrm{E}-01$ & $2.958 \mathrm{E}-02$ & $8.055 \mathrm{E}-02$ \\
\hline $8.000 \mathrm{E}-01$ & $2.889 \mathrm{E}-02$ & $7.074 \mathrm{E}-02$ \\
\hline $1.000 \mathrm{E}+00$ & $2.797 \mathrm{E}-02$ & $6.358 \mathrm{E}-02$ \\
\hline $1.250 \mathrm{E}+00$ & $2.675 \mathrm{E}-02$ & $5.687 \mathrm{E}-02$ \\
\hline $1.500 \mathrm{E}+00$ & $2.557 \mathrm{E}-02$ & $5.175 \mathrm{E}-02$ \\
\hline $2.000 \mathrm{E}+00$ & $2.359 \mathrm{E}-02$ & $4.447 \mathrm{E}-02$ \\
\hline $3.000 \mathrm{E}+00$ & $2.076 \mathrm{E}-02$ & $3.581 \mathrm{E}-02$ \\
\hline $4.000 \mathrm{E}+00$ & $1.894 \mathrm{E}-02$ & $3.079 \mathrm{E}-02$ \\
\hline $5.000 \mathrm{E}+00$ & $1.770 \mathrm{E}-02$ & $2.751 \mathrm{E}-02$ \\
\hline $6.000 \mathrm{E}+00$ & $1.683 \mathrm{E}-02$ & $2.522 \mathrm{E}-02$ \\
\hline $8.000 \mathrm{E}+00$ & $1.571 \mathrm{E}-02$ & $2.225 \mathrm{E}-02$ \\
\hline $1.000 \mathrm{E}+01$ & $1.506 \mathrm{E}-02$ & $2.045 \mathrm{E}-02$ \\
\hline $1.500 \mathrm{E}+01$ & $1.434 \mathrm{E}-02$ & $1.810 \mathrm{E}-02$ \\
\hline $2.000 \mathrm{E}+01$ & $1.415 \mathrm{E}-02$ & $1.705 \mathrm{E}-02$ \\
\hline
\end{tabular}

\section{A.3 Conversion Factors}

The response from the instrument used to establish a radiation test field should be corrected at the energy of interest based on calibration information provided by the manufacturer or by measurement.

Correction factors can be estimated at the energy of interest from the manufacturer's energy response curve or laboratory measurements. A response curve provided in the instrument manual from a commercial pressurized-ion chamber is shown in Figure 3. In Figure 3, the instrument's relative response to ${ }^{137} \mathrm{Cs}$ equals the value of the applied field (i.e., the energy correction factor equals 1 ) and the instrument's displayed response equals the applied exposure rate. However, for ${ }^{241} \mathrm{Am}$, with a photon energy of $\approx 60 \mathrm{keV}$, the relative response value is approximately 1.1. Therefore, the instrument will display a value that is $110 \%$ of the applied exposure rate. The user would then need to divide the measured readings by 1.1 to get a more accurate measurement of the applied radiation field value.

Care should be taken when using the information provided in the instrument manuals as it can be a generic energy response curve that does not fully describe the response of the instrument used in the measurements. Figure 4 shows an example of the difference in the energy response provided in the instrument manual and the values from the calibration of the instrument using NIST beams. Calibration measurements were also performed with ${ }^{137} \mathrm{Cs}$ beams, ${ }^{60} \mathrm{Co}$ beams and x-ray beams, yielding average energies of $60 \mathrm{keV}$ (LK70 at $141 \mathrm{mR} / \mathrm{h}$ and $271 \mathrm{mR} / \mathrm{h}$ ), 65 $\mathrm{keV}$ (NS80 at $719 \mathrm{mR} / \mathrm{h}$ ), $83 \mathrm{keV}$ (NS100 at $424 \mathrm{mR} / \mathrm{h}$ ), $87 \mathrm{keV}$ (LK100 at $181 \mathrm{mR} / \mathrm{h}$ and 357 $\mathrm{mR} / \mathrm{h}$ ), $109 \mathrm{keV}$ (LK125 at $255 \mathrm{mR} / \mathrm{h}$ ), $149 \mathrm{keV}$ (LK170 at $216 \mathrm{mR} / \mathrm{h}$ ), and $211 \mathrm{keV}$ (LK240 at $424 \mathrm{mR} / \mathrm{h}$ ) [Ref. A.9]. 


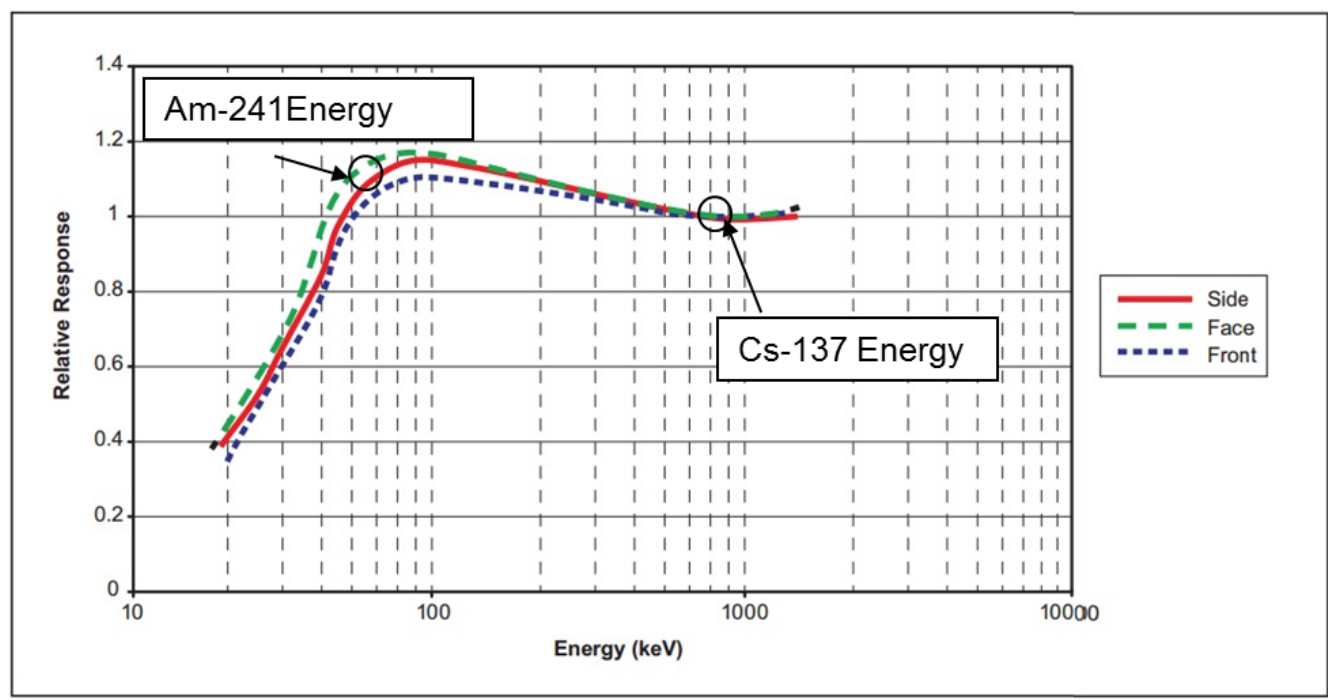

Figure 3: Energy response from a pressurized-ion chamber when measured from side, front and marked face of the instrument.

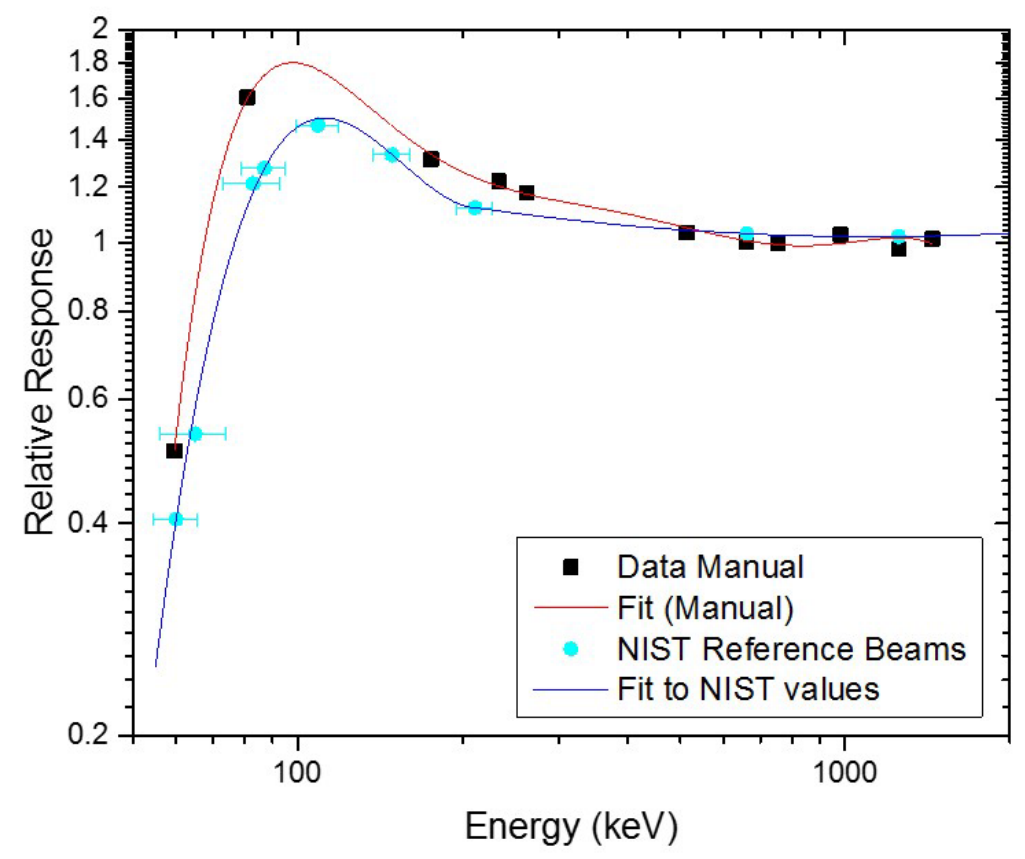

Figure 4: Energy response provided by the instrument manual and the calibration values from a pressurized-ion chamber. Uncertainty values are not provided in the instrument manual, the uncertainties in the y-axis NIST values smaller than the symbol size, uncertainties are given with a coverage factor of $k=1$.

Instruments measuring ambient dose equivalent rate are sometimes used to determine the values of exposure rate or vice-versa. In these cases, conversion coefficients should be used in order to determine the desired radiation field.

The conversion coefficients used for these calculations are obtained from the ISO 4037-3 standard. This standard provides conversion coefficients from Sv to Gy. 
As an example, the conversion coefficients from Gy to Sv from the ISO 4037-3 standard [Ref. A.8] are:

- For ${ }^{137} \mathrm{Cs}: 1.20 \mathrm{~Sv} / \mathrm{Gy}$

- For ${ }^{60} \mathrm{Co}: 1.16 \mathrm{~Sv} / \mathrm{Gy}$

- For ${ }^{241} \mathrm{Am}: 1.74 \mathrm{~Sv} / \mathrm{Gy}$

To obtain the exposure rate, an additional conversion from Gy to R should be used. For this conversion, the following factors should be used:

- For ${ }^{137} \mathrm{Cs}: 113.92 \mathrm{R} / \mathrm{Gy}$

- For ${ }^{60} \mathrm{Co}: 113.74 \mathrm{R} / \mathrm{Gy}$

- For photons less than $200 \mathrm{keV}$ (for example, x-rays, ${ }^{241} \mathrm{Am}$ ) - 114.10 R/Gy

\section{A.4 References}

[A.1] Seltzer, S.M., Air-Kerma-Rate Coefficients for Selected Photon-Emitting Radionuclide Sources, National Institute of Standards and Technology publication NISTIR 7092A (2004).

[A.2] National Institute of Standards and Technology (NIST), 2012, XCOM: Photon Cross Sections Database, available online at http://physics.nist.gov/PhysRefData/Xcom/html/xcom1.html.

[A.3] LNE-LNHB, Le Laboratoire National Henri Becquerel, Table of Radionuclides, http://www.nucleide.org/DDEP_WG/DDEPdata.htm.

[A.4] ENSDF, Evaluated Nuclear Structure Data File, National Nuclear Data Center, Chart of Nuclides, http://www.nndc.bnl.gov/.

[A.5] Boutillon M, Perroche-Roux AM. Re-evaluation of the $\mathrm{W}$ value for electrons in dry air. Phys. Med. Biol. 32, No 2: 213-219, 1987.

[A.6] Tables of $x$-ray mass attenuation coefficients and mass energy-absorption coefficients $1 \mathrm{keV}$ to $20 \mathrm{MeV}$ for elements $\mathrm{Z}=1$ to 92 and 48 additional substances of dosimetric interest, NISTIR 5632, J.H. Hubbell and S.M. Seltzer, May 2005, http://www,nist,gov/pml/data/xraycoef/.

[A.7] The physics of radiology, $4^{\text {th }}$ Edition, Publisher Charles C. Thomas, Authors: Harold Elford Johns and John Robert Cunningham (1983).

[A.8] ISO 4037-3-1999, $\mathrm{X}$ and gamma reference radiation for calibrating dosemeters and doserate meters and for determining their response as a function of photon energy -- Part 3: Calibration of area and personal dosemeters and the measurement of their response as a function of energy and angle of incidence.

[A.9] NIST Technical Note 1916. Methods for characterizing a radiation detector for specifying radiation fields during testing against standards for homeland security applications. A. L. Sallaska, L. Pibida, R. Minniti, M. O’Brien. Radiation Physics Division. Physical Measurement Laboratory. http://dx.doi.org/10.6028/NIST.TN.1916. April 2016. 


\section{Appendix B: Fluence rate and efficiency calculations}

\section{B1. Fluence Rate Calculations}

Radiation from an X-ray generator or a radioactive source consists of a beam of photons, usually with a variety of energies. If we consider that the beam is monoenergetic, then one way to describe the beam would be to specify the number of photons, $d N$, that would cross an area, $d a$, taken at right angles to the beam. The ratio of these would yield what the International Commission of Radiological Units and Measurements (ICRU 60) has called fluence or photon fluence represented by the capital Greek letter phi.

$$
\Phi=\frac{\mathrm{dN}}{\mathrm{da}}
$$

At times, one may be interested in the number of photons that pass through unit area per unit time. This is called the fluence rate and it is represented by the lower case Greek letter phi, thus:

$$
\dot{\phi}=\frac{d \Phi}{d t}=\frac{d N}{d a d t}
$$

When the emission of the source is isotropic and we integrate equation (B.2), we have that the fluence rate at a radius, $r$, from the source can be expressed as:

$$
\dot{\phi}=\frac{R}{4 \pi r^{2}}
$$

where $R$ is the number of photons per second emitted from the source. For a point source the number of photons per second emitted from the source is equal to the source activity times the emission probability of a gamma ray at energy $E$.

If the source is encapsulated in a material, $R$ can be express as a function of the source activity, A (expressed in Becquerel), as:

$$
R=A * p(E) * \exp [-(\mu / \rho) x \rho] * B
$$

where $p(E)$ is the emission probability of a gamma ray at energy $E$, and the source is encapsulated by layer of material with thickness, $x$ (expressed in $\mathrm{cm}$ ), density $\rho$ (expressed in $\left.\mathrm{g} / \mathrm{cm}^{3}\right), B$ is the build-up factor, and $\mu / \rho$ is the mass attenuation coefficient of the material (expressed in units of $\mathrm{cm}^{2} / \mathrm{g}$ ). Then the fluence rate at a radius, $r$, from the source can be expressed as: 


$$
\dot{\phi}=\frac{A * p(E) * B * \exp [-(\mu / \rho) x \rho]}{4 \pi r^{2}}
$$

If the source emits gamma rays at different energies, then the fluence rate can be expressed as:

$$
\dot{\phi}=\frac{A}{4 \pi r^{2}} \sum_{i} p\left(E_{i}\right) B_{i} \exp \left[-(\mu / \rho)_{i} x \rho\right]
$$

Note that the fluence rate value obtained using equation (B.6) will depend on the cutoff energy used in the calculation. Most radiation detection instruments have difficulties detecting gamma rays with energies lower than $30 \mathrm{keV}$.

The emission probabilities listed in the Evaluated Nuclear Structure Data File (ENSDF, Ref. B.1) are used for these calculations. These data can be obtained from: http://www.nndc.bnl.gov/.

If the required data are not available in ENSDF a list of the photo peaks and emission probabilities used in the calculation need to be provided as part of the support documentation.

If the source is a point source of unknown activity (i.e., isotropic emission), the fluence rate for a single gamma-ray line of energy, $E$, can be measured using a gamma-ray spectrometer equipped with a HPGe or $\mathrm{NaI}(\mathrm{Tl})$ detector. In this case the fluence rate can be expressed as:

$$
\dot{\phi}=\frac{\text { Area }_{\text {net }}}{T_{\text {live }} \epsilon(E) * 4 \pi r^{2}}
$$

where Area $_{\text {net }}$ is the net photo-peak area of the gamma line of energy $E, \varepsilon(E)$ is the detector full-energy peak efficiency for the gamma ray of energy $E$, and $T_{\text {live }}$ is the live time of the measurement (expressed in seconds) [Ref. B.2]. This calculation assumes that the sources used for the detector efficiency calibration have the same encapsulation and they are measured in the same geometry and distance as the unknown sources. If this is not the case, the necessary corrections should be applied to the measurements.

Additional correction to the detector full-energy peak efficiency and/or net photo-peak area may be needed depending on the measurement conditions. These corrections may include the following: decay of the source during the measurement time, the source self-attenuation, attenuation and build-up factor through air from the source location to the detector location, attenuation through shielding material, build-up factor of shielding material, pile-up correction, coincidence summing correction and differences in source geometry (e.g., differences of HPGe calibration to measurement geometries), see section B.3. 


\section{B.2 Full-Energy-Peak Efficiency Calculations}

The full-energy-peak efficiency is determined for a fixed source geometry (i.e., source-todetector distance, source height, and source encapsulation) can be determined from gammaray lines in the gamma-ray spectrum by:

$$
\epsilon(E)=\frac{\text { Area }_{\text {net }}}{A \times T_{\text {live }} \times P_{\gamma}} \sum_{c} C_{i}
$$

where the $A r e a_{n e t}$ is the net photo-peak area of the gamma-ray of energy $E, A$ is the source activity at the time of the measurement (expressed in Becquerel), $T_{\text {live }}$ is the measurement live time, $P_{\gamma}$ is the emission probability of the gamma-ray of energy $E$ and $C_{i}$ are the correction coefficients.

Correction coefficients to account for the source encapsulation and measurement distance need to be applied to the efficiency if the efficiency measurements and the source measurements are performed using different source geometries. Several corrections to the detector full-energy peak efficiency and/or net photopeak area may be needed depending on the measurement conditions. These corrections may include the decay of the source during the measurement time, the source self-attenuation, attenuation and build-up factor through air from the source location to the detector location, attenuation through shielding material, build-up factor of shielding material, pile-up correction, coincidence summing correction and differences in source geometry (e.g., differences of HPGe calibration to measurement geometries), see Ref. B3.

The detector efficiency is typically fitted when plotted in a ln-ln (natural logarithm) or log-log (logarithm base 10) scale by a polynomial function, see IEC 61452 [Ref. B.5] and equations B.9 and B.10. In many cases a spline function with a cross over point at approximately $200 \mathrm{keV}$ gives smaller residuals to the fit. One may choose one of the commonly used functions below to fit the efficiency curve, see Figure 5 as an example. It is also important to look at the residuals of the fit to assess the goodness of the fit, see Figure 6.

$$
\begin{aligned}
& \ln \varepsilon(\mathrm{E})=\sum_{i=0}^{n} p_{i}(\ln E)^{i} \\
& \log \varepsilon(\mathrm{E})=\sum_{i=0}^{n} p_{i}(\log E)^{i}
\end{aligned}
$$

The degree of the polynomial, $n$, depends on the number of calibration points available:

$$
\begin{aligned}
& n=5 \text { for ten or more calibration points } \\
& n=4 \text { for eight or nine calibration points } \\
& n=3 \text { for six or seven calibration points } \\
& n=2 \text { for three or five calibration points }
\end{aligned}
$$




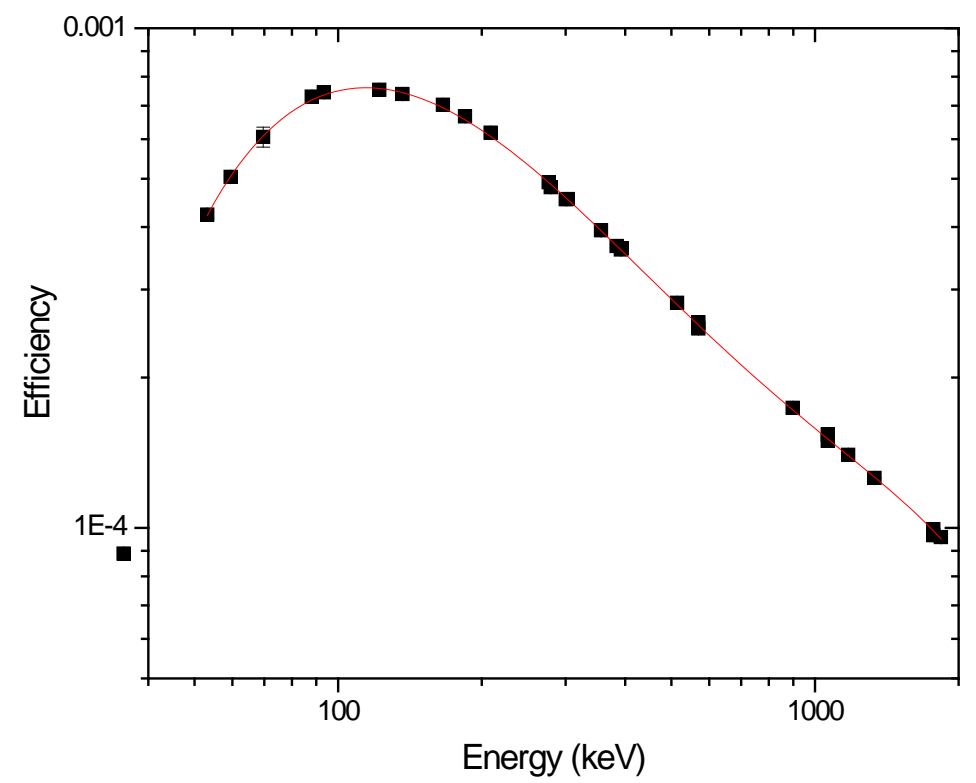

Figure 5: Full-energy peak efficiency curve for HPGe detector and associated fitting curve. Uncertainties are smaller than the symbol size, uncertainties are given with a coverage factor of $k=1$.

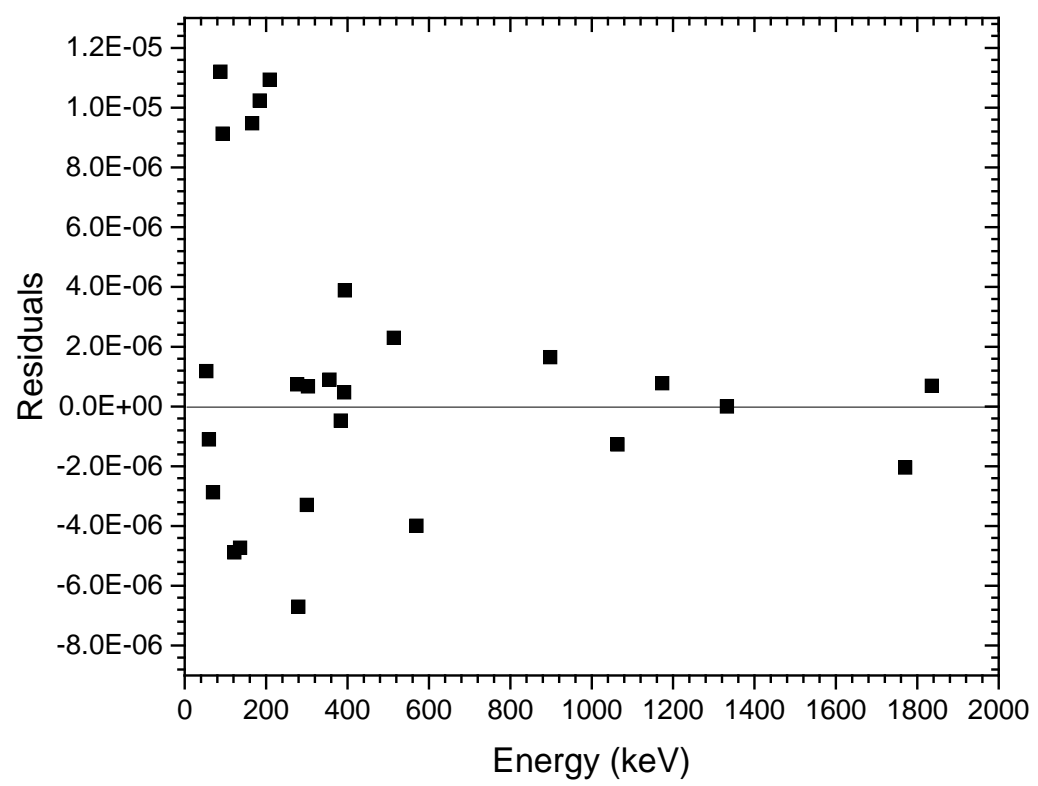

Figure 6: Residuals from polynomial fit to full-energy peak efficiency curve for HPGe

\section{B.3 Possible correction coefficients}


The most common corrections used for different gamma-ray spectrometry measurements using HPGe detectors are listed below. Additional corrections may be needed depending on the type of performed measurements [Ref. B.4].

\section{B.3.1 Decay correction during measurement}

If there is a need to determine the source activity for radionuclides with half-lives that are short compared to the measurement time, it is necessary to account for the decay during the counting interval. It is recommended to correct at the midpoint of the counting time interval, so the correction factor is:

$$
C_{d}=\frac{\lambda T_{r}}{\left(1-e^{-\lambda T_{r}}\right)}
$$

where $\lambda$ is the decay constant $\ln (2) / T_{1 / 2}, T_{1 / 2}$ is the half-life, and $T_{\mathrm{r}}$ is the time interval over which the source decays, corresponding to the run (or real) time of the measurement.

\section{B.3.2 Decay factor correction to a reference time}

If several measurements for a given source are performed at different times and the results need to be combined and reported at a given reference time then the activity needs to be corrected, and the correction factor is

$$
C_{d f}=e^{-\lambda t}
$$

where $\lambda$ is the decay constant $\ln (2) / T_{1 / 2}, T_{1 / 2}$ is the half-life, and $t$ is the time interval over which the source decays between the reference time and the measurement time.

\section{B.3.3 Pile-up or dead time correction}

If the count rate in the detector is high pile-up may occur due to dead-time. To correct for this effect, it is needed to determine the loss in photopeak as a function of increase total count rate in the detector, these needs to be verified for different gamma-ray energies. There are two techniques that can be used to perform this correction [Ref. B.4].

a. This can be accomplished by measurements with a set of sources containing known relative amounts of different photon emitting radionuclides with energies in the region of interest. Such a set of sources containing: ${ }^{57} \mathrm{Co},{ }^{133} \mathrm{Ba},{ }^{54} \mathrm{Mn}$ and ${ }^{65} \mathrm{Zn}$ with activity ratios of approximately 1:3:6:10:15. If no pile-up losses occur the ratios of the measured peak area $N_{i}(i=1,2, \ldots)$ and the activity $A_{i}$ should be independent of the total count rate, provided that the same analyzer live-time interval $T_{l}$ is chosen each time. For each energy, the ratios $N_{i} /\left(A_{i} T_{l}\right)$ can be fitted by a linear function of the total count 
rate $n_{t}$. This rate is defined as the total number of counts stored in the entire spectrum, $N_{t}$, divided by the live-time; that is $n_{t}=N_{t} / T_{l}$.

b. This can also be accomplished by using two sources whose activities need not be known. One source needs to be weak with one photon energy $E_{1}$ (e.g., ${ }^{137} \mathrm{Cs}$ ) and it need to be kept at a fixed position. The second source needs to be stronger and have a gamma-ray with an energy lower than $E_{1}$ (e.g., ${ }^{57} \mathrm{Co}$ ), this source is moved at different distances of the detector in order to change the total measured count rate. The count rate of the peak corresponding to the energy $E_{1}$ is plotted as a function of $n_{t}=N_{t} / T_{l}$. The data is fitted by a straight line. The correction $C_{p}=1 / e^{-\tau N t}, e^{-\tau N t} \approx 1-\tau N_{t}$ where $\tau$ is the slope of the linear fit.

\section{B.3.4 Coincidence summing correction}

The correction depends on the decay scheme of the radionuclide under measurement [Ref. B.4, B.5]. There are several ways to compute the magnitude of this correction. There are several software packages that can perform these calculations. These corrections are not needed if the measured radionuclides are the same as the calibration radionuclides and if the source-todetector distance and source geometry are kept the same for the calibration and the source measurements. These corrections are a function of the total and full-energy-peak efficiencies;

the general functional form is $C_{s}=\frac{1}{1 \pm \epsilon_{i}}$ (the exact formula depends on the number of gammarays with different energies that are emitted within the resolving time of the spectrometer). If the efficiency values are of the order of $10^{-3}$ then the correction will be smaller than $0.1 \%$. These efficiency values can be achieved by measuring at a faraway distance or by using small detectors.

\section{B.3.5 Source geometry, encapsulation, shielding or self-attenuation}

If the source geometry used for the measurements is the same as the one used for the HPGe detector calibration, then no correction is needed. These corrections, when needed, take into account the differences in solid angle between the source and the detector as well as the differences in the source-to-detector distance, attenuation through air, self-attenuation in the source and attenuation through any changes in possible shielding surrounding the source [Ref. B.4]. There are several software packages that can perform these calculations.

The attenuation through material (i.e., air, self-attenuation, shielding) can be corrected using the mass attenuation coefficients as follows:

$$
C_{A t t}=\frac{1}{e^{-[(\mu / \rho) x \rho]}}
$$

where $\mu / \rho$ is the mass attenuation coefficient (in $\mathrm{cm}^{2} / \mathrm{g}$ ), $\mathrm{x}$ is the material thickness (in $\mathrm{cm}$ ) and $\rho$ is the material density (in $\mathrm{g} / \mathrm{cm}^{3}$ ). Mass attenuation coefficients and material densities can be obtained from XCOM [Ref. B.7]. 
If the experimental efficiency calibration has been performed at a distance $d_{0}$ and the spectral measurements at a distance $d$, in the case of a point source positioned at the symmetry axis of the detector, the efficiency can be corrected as:

$$
\frac{\epsilon(d)}{\epsilon\left(d_{0}\right)}=\frac{\Omega(d)}{\Omega\left(d_{0}\right)}
$$

For a circular detector of radius $R_{D}$ and zero thickness the solid angle is calculated as:

$$
\Omega(d)=2 \pi\left[1-\left(1+\frac{R_{D}^{2}}{d^{2}}\right)^{-\frac{1}{2}}\right]
$$

This approximation is valid as long as $d$ and $d_{0}$ are larger in comparison with $R_{D}$. At low energies (e.g., $60 \mathrm{keV}$ ) the approximation given by equation (B.14) cannot be used as the detector thickness as well as the detector dead layer and the distance between the detector and the end cap need to be accounted for in the correction. If the efficiency calibration was performed using a point source and the source being measured has a larger area, corrections should be made to account for these differences.

A point source is a source with dimensions smaller than the detector dimensions and the source-to-detector distance. An area source is one for which the thickness is small so attenuation and geometrical effects do not need to be accounted for.

For additional information about these different corrections see reference [Ref. B.4].

\section{B.4 Uncertainty calculation}

The uncertainty on the full-energy peak efficiency is obtained using uncertainty propagation, assuming that all measured quantities are independent. Therefore, when there is no correlation, the uncertainty for the full-energy peak efficiency, $\varepsilon$, is given by

$$
u_{\varepsilon}=\sqrt{\left(\frac{\partial \varepsilon}{\partial N}\right)^{2} u_{N}^{2}+\left(\frac{\partial \varepsilon}{\partial T_{l}}\right)^{2} u_{T_{l}}^{2}+\left(\frac{\partial \varepsilon}{\partial A}\right)^{2} u_{A}^{2}+\left(\frac{\partial \varepsilon}{\partial P}\right)^{2} u_{P}^{2}+\sum_{i}\left(\frac{\partial \varepsilon}{\partial C_{i}}\right)^{2} u_{C i}^{2}}
$$

where $u_{N}, u_{T}, u_{A}(E), u_{P}$, and $u_{C i}$ are the uncertainties associated with the quantities $N(E), T, A$, $P(E)$, and $C_{i}$, respectively. The nominal uncertainty range is approximately between $2-5$ percent (expanded uncertainties, $\mathrm{k}=2$ ).

If there is correlation, the uncertainty is evaluated using the technique described is Ref. B.8 and B.9 "Guide to the expression of uncertainty in measurement (GUM)". A tool created by the NIST Statistical Engineering Division can be used to compute the correlation matrix as described in the GUM. This tool can run in Excel or in $R$ programs [Ref. B.10] and can be downloaded from the NIST website [Ref. B.11].

\section{B.5 Emission probabilities and nuclear data}


It is recommended that the nuclear data used to determine the efficiencies is obtained from Laboratoire National Henri Becquerel, Atomic and Nuclear Data (Ref. B.3). If Ref. B.3 does not contain the required information, then the values listed in the National Nuclear Data Center (Ref. B.1) should be used.

\section{B.6 References}

[B.1] National Nuclear Data Center (NNDC), Evaluated Nuclear Structure Data File (ENSDF), http://www.nndc.bnl.gov/ensdf/index.jsp.

[B.2] The physics of radiology, $4^{\text {th }}$ Edition, Publisher Charles C. Thomas, Authors: Harold Elford Johns and John Robert Cunningham (1983).

[B.3] Laboratoire National Henri Becquerel, Atomic and Nuclear Data, Recommended Data (LNE-LNHB), http://www.nucleide.org/

[B.4] Gamma- and X-ray Spectrometry with Semiconductor Detectors. K. Debertin and R.G. Helmer. Editor North-Holland. 1998 Edition.

[B.5] IEC 61452. Nuclear Instrumentation - Measurement of gamma-ray emission rates of nuclides - Calibration and use of germanium spectrometers

[B.6] ANSI N42.14-1999, American National Standard for Calibration and Use of

Germanium Spectrometer for the Measurement of Gamma-Ray Emission Rates of Radionuclides.

[B.7] XCOM: Photon Cross Sections Database. NIST Standard Reference Database 8 (XGAM). M.J. Berger, J.H. Hubbell, S.M. Seltzer, J. Chang, J.S. Coursey, R. Sukumar, D.S. Zucker, and K. Olsen.

[B.8] Taylor, B. N., and Kuyatt, C. E., “Guidelines for Evaluating and Expressing the Uncertainty of NIST Measurement Results”, National Institute of Standards and Technology Technical Note 1297, Sep. 1994.

[B.9] Joint Committee for Guides in Metrology, Evaluation of measurement data - Guide to the expression of uncertainty in measurement (GUM), JCGM 100:2008.

[B.10] R, The R Project for Statistical Computing, http://www.r-project.org/, (http://cran.rstudio.com/) and (https://www.rstudio.com/ide/download/desktop).

[B.11] NIST, http://www.nist.gov/itl/sed/gsg/metrology-for-microsoft-excel.cfm. 2017 


\section{Appendix C: Identifying mutually orthogonal (perpendicular) planes}

First, superimpose the Cartesian coordinate system over the EUT (see Figure 7).

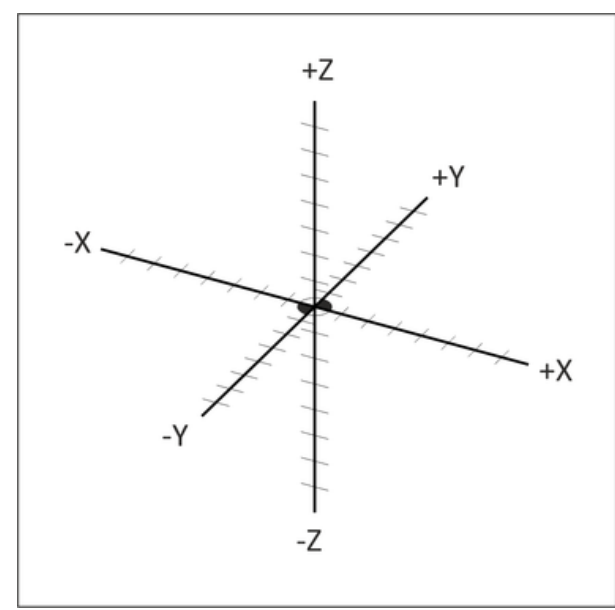

Figure 7: Cartesian coordinate system.

$\mathrm{X}$ plane - Also referred to as transverse or lateral. Mutually perpendicular to $\mathrm{Z}$ and $\mathrm{Y}$ and parallel to ground plane.

Y plane - Also referred to as longitudinal - parallel to ground plane.

$\mathrm{Z}$ plane - Also referred to as vertical - perpendicular to ground plane. Always toward tracking changes that may be needed during testing Earth's center.

Using the Cartesian coordinate system and referencing to the way the user will use the EUT or EUT's usage, one should be able to figure out the XYZ planes from any picture and any type of instrument.

Finally, identify and number the sides of the EUT. This can be done by using a numbering system or the Cartesian system of planes, as shown in Table C.1.

Table C.1: Numbered EUT sides and the corresponding cartesian coordinate reference.

\begin{tabular}{|c|c|c|}
\hline$X$ & Right & 1 \\
\hline$-X$ & Left & 2 \\
\hline$Y$ & Front & 3 \\
\hline$-Y$ & Back & 4 \\
\hline$Z$ & Top & 5 \\
\hline$-Z$ & Bottom & 6 \\
\hline
\end{tabular}




\section{Appendix D: List of standards}

\section{List of published ANSI and IEC standards related to homeland security applications for radiation detection instruments are the following:}

\begin{tabular}{|c|c|}
\hline ANSI/IEEE standards & IEC standards \\
\hline $\begin{array}{l}\text { ANSI/IEEE N42.32 } \\
\text { Performance Criteria for Alarming Personal Radiation Detectors } \\
\text { for Homeland Security }\end{array}$ & $\begin{array}{l}\text { IEC } 62401 \\
\text { Radiation protection instrumentation - Alarming personal } \\
\text { radiation devices (PRD) for detection of illicit trafficking of } \\
\text { radioactive material }\end{array}$ \\
\hline $\begin{array}{l}\text { ANSI/IEEE N42.33 } \\
\text { Portable Radiation Detection Instrumentation for Homeland } \\
\text { Security }\end{array}$ & $\begin{array}{l}\text { IEC } 62533 \\
\text { Radiation protection instrumentation - Highly sensitive hand-held } \\
\text { instruments for photon detection of radioactive material }\end{array}$ \\
\hline $\begin{array}{l}\text { ANSI/IEEE N42.34 } \\
\text { Performance Criteria for Hand-held Instruments for the } \\
\text { Detection and Identification for Radionuclides }\end{array}$ & $\begin{array}{l}\text { IEC } 62327 \\
\text { Radiation protection instrumentation - Hand-held instruments for } \\
\text { the detection and identification of radionuclides and for the } \\
\text { indication of ambient dose equivalent rate from photon radiation }\end{array}$ \\
\hline $\begin{array}{l}\text { ANSI/IEEE N42.35 } \\
\text { Evaluation and Performance of Radiation Detection Portal } \\
\text { Monitors }\end{array}$ & $\begin{array}{l}\text { IEC } 62244 \\
\text { Radiation protection instrumentation - Installed radiation monitors } \\
\text { for the detection of radioactive and special nuclear materials at } \\
\text { national borders }\end{array}$ \\
\hline $\begin{array}{l}\text { ANSI/IEEE N42.38 } \\
\text { Performance Criteria for Spectroscopy-Based Portal Monitors } \\
\text { Used for Homeland Security }\end{array}$ & $\begin{array}{l}\text { IEC } 62484 \\
\text { Radiation protection instrumentation - Spectroscopy-based portal } \\
\text { monitors used for the detection and identification of illicit } \\
\text { trafficking of radioactive material }\end{array}$ \\
\hline $\begin{array}{l}\text { ANSI/IEEE N42.43 } \\
\text { Performance Criteria for Mobile and Transportable Radiation } \\
\text { Monitors Used for Homeland Security }\end{array}$ & $\begin{array}{l}\text { IEC } 63121 \\
\text { Radiation protection instrumentation - Vehicle-mounted mobile } \\
\text { systems for the detection of illicit trafficking of radioactive } \\
\text { materials }\end{array}$ \\
\hline $\begin{array}{l}\text { ANSI/IEEE N42.48 } \\
\text { Performance Requirements for Spectroscopic Personal Radiation } \\
\text { Detectors (SPRDs) for Homeland Security }\end{array}$ & $\begin{array}{l}\text { IEC } 62618 \\
\text { Radiation protection instrumentation - Spectroscopy-based } \\
\text { alarming Personal Radiation Detectors (SPRD) for the detection } \\
\text { of illicit trafficking of radioactive material }\end{array}$ \\
\hline $\begin{array}{l}\text { ANSI/IEEE N42.53 } \\
\text { Performance Criteria for Backpack Based Radiation Detection } \\
\text { Systems Used for Homeland Security }\end{array}$ & $\begin{array}{l}\text { IEC } 62694 \\
\text { Radiation protection instrumentation - Backpack-type radiation } \\
\text { detector (BRD) for detection of illicit trafficking of radioactive } \\
\text { material }\end{array}$ \\
\hline $\begin{array}{l}\text { No ANSI/IEEE standard currently available for highly sensitive } \\
\text { neutron detectors }\end{array}$ & $\begin{array}{l}\text { IEC } 62534 \\
\text { Radiation protection instrumentation - Highly sensitive hand-held } \\
\text { instruments for neutron detection of radioactive material }\end{array}$ \\
\hline
\end{tabular}

Technical capability standards (TCSs) for radioisotope identification devices (RIIDs), backpack-type radiation detector (BRD), radiation portal monitors (RPMs), aerial systems, and mobile systems were also developed. 


\section{Appendix E: Statistical tools}

\section{E.1 Coefficient of Variation}

Testing of radiation detection instruments includes evaluating the instruments' performance when subjected to different environmental, mechanical and electromagnetic influence quantities. Such tests involve collecting instrument readings before (pre-test) and after (posttest) the exposure to these influence quantities. In order to minimize the testing time, the number of pre-test and post-test instrument readings is limited to 10 . The standards require that the test setup is such that the strength of the radiation field allows the radiation detection instruments to display a coefficient of variation in their pre-test readings that is less than a specified value (typically less than $12 \%$ ). For most instruments, the acceptance requirement is that the instrument's post-test readings must be within $15 \%$ of its pre-test readings.

The coefficient of variation, $V$, is defined as the ratio of the standard deviation, $s$, to the arithmetic mean, $\bar{x}$, of a set of $n$ measurements $x_{i}, i=1, \ldots, n$, given by the following formula:

$$
V=\frac{1}{\bar{x}} \sqrt{\frac{1}{(n-1)} \sum_{i=1}^{n}\left(x_{i}-\bar{x}\right)^{2}},
$$

where $\bar{x}=\frac{1}{n} \sum_{i=1}^{n} x_{i}$

In order to achieve the required coefficient of variation in the instrument readings (typically less than $12 \%$ ), the strength of the radiation field used for testing often needs to be adjusted when using weak sources. Normally, larger radiation fields imply lower coefficient of variation values as the measured signal is larger than the background radiation levels, reducing the uncertainty of the measurements. This can be achieved by moving a weak source closer to the instrument under test.

During recent testing of radiation detection instruments against different influence quantities (e.g., temperature, humidity) it was observed that the coefficient of variation for gamma-ray measurements varied between $0.5 \%$ and $10 \%$, with typical values between $2 \%$ and $6 \%$ for radiation fields varying approximately between $100 \mu \mathrm{R} / \mathrm{h}$ and $1 \mathrm{mR} / \mathrm{h}$. For neutrons, the coefficient of variation varied between $8 \%$ and $25 \%$, though the value of the radiation field used for the test was unclear, as a source with an emission rate of approximately $2 \times 10^{4} \mathrm{~s}^{-1}$ was used but the source to detector distance was not always recorded. For background measurements the coefficient of variation varied typically between $5 \%$ and $50 \%$, although in few cases values up to $100 \%$ were observed.

These recent measurements also showed that not only did the mean instrument readings change, but the variation of the readings also changed when testing different influence quantities (e.g., temperature going from $20^{\circ} \mathrm{C}$ (pre-test) to $40{ }^{\circ} \mathrm{C}$ (post-test)). Therefore, consideration should be given to include instrument reading variability as an additional acceptance requirement. This will require developing a test for comparing the pre- and posttest variances, currently not addressed by the described approach. 


\section{E.2 Hypothesis Test}

As radiation particle emission and detection are stochastic processes, comparing the pre- and post-test instrument readings must be addressed from a statistical point of view. The current practice of requiring the pre- and post-test sample means to be within $15 \%$ of one another does not go far enough in considering the stochastic nature of the process. Under such policies instruments that provide a truly acceptable performance may fail to meet the standards due to an "unlucky" test sample. The uncertainty in the instrument readings must also be considered when establishing a comparison policy. To this end, we formulate the following assumptions and requirements:

1. The pre- and post-test exposure rates (count rates) provided by a detection instrument are average exposures (counts) over a period of time, and thus, per the Central Limit Theorem, are reasonably modelled by normal random variables with unknown mean and variance: $X_{\text {pre }} \sim N\left(\mu_{\text {pre }}, \sigma_{\text {pre }}^{2}\right)$ and $X_{\text {post }} \sim N\left(\mu_{\text {post }}, \sigma_{\text {post }}^{2}\right)$ [Ref. E.1].

2. The number of pre-test instrument observations, $n_{1}$, will equal the number of post-test instrument observations, $n_{2}$, specifically, $n_{1}=n_{2}=10$.

3. Except for background and neutron radiation measurements, the coefficient of variation for the pre-test response will not exceed $12 \%$, that is, $\frac{\sigma_{\text {pre }}}{\mu_{\text {pre }}} \leq 0.12$ ( $12 \%$ is chosen for this example as it was the value used in most standards; $8 \%$ is used in one standard, as is discussed at the end of this section).

4. An instrument is considered acceptable (satisfies the requirement) if its post-test mean, $\mu_{\text {post }}$, is within $15 \%$ of its pre-test mean, $\mu_{\text {pre. }}$. Otherwise, the instrument is considered unacceptable.

5. Instruments are assumed to be acceptable until the data proves otherwise.

In order to formulate these assumptions and requirements mathematically we use a hypotheses test. In this formulation, we initially assume that an instrument is acceptable by stating the null hypothesis, $H_{0}$, to be that $\mu_{\text {post }}$ is within $15 \%$ of $\mu_{\text {pre }}$; the alternative hypothesis, $H_{1}$, is then stated as the instrument is unacceptable:

$$
\begin{array}{ll}
H_{0}: & 0.85 \mu_{\text {pre }} \leq \mu_{\text {post }} \leq 1.15 \mu_{\text {pre }} \Rightarrow \mu_{\text {post }}-0.85 \mu_{\text {pre }} \geq 0 \text { and } \mu_{\text {post }}-1.15 \mu_{\text {pre }} \leq 0 \\
H_{1}: & \mu_{\text {post }}<0.85 \mu_{\text {pre }} \text { or } \mu_{\text {post }}>1.15 \mu_{\text {pre }} \Rightarrow \mu_{\text {post }}-0.85 \mu_{\text {pre }}<0 \text { or } \mu_{\text {post }}-1.15 \mu_{\text {pre }}>0
\end{array}
$$

Given the pre-test instrument observations $x_{\text {pre, }, 1}, \ldots, x_{\text {pre, }}$ and the post-test instrument observations $x_{\text {poss }, 1}, \ldots, x_{\text {poss }, n_{2}}$, the following sample statistics are calculated:

- The pre- and post-test sample means:

$\bar{x}_{\text {pre }}=\frac{1}{n_{1}} \sum_{i=1}^{n_{1}} x_{\text {pre }, i}$ and $\bar{x}_{\text {post }}=\frac{1}{n_{2}} \sum_{i=1}^{n_{2}} x_{\text {post }, i}$.

- The pre- and post-test sample standard deviations:

$s_{\text {pre }}=\sqrt{\frac{\sum_{i=1}^{n_{1}}\left(x_{\text {pre }, i}-\bar{x}_{\text {pre }}\right)^{2}}{n_{1}-1}}$ and $s_{\text {post }}=\sqrt{\frac{\sum_{i=1}^{n_{2}}\left(x_{\text {pos }, i}-\bar{x}_{\text {post }}\right)^{2}}{n_{2}-1}}$. 
Two test statistics based on a two-sample t-test [Ref. E.2] are calculated:

$$
t_{1}=\frac{\bar{X}_{\text {post }}-0.85 \bar{X}_{\text {pre }}}{\sqrt{\frac{s_{\text {post }}^{2}}{n_{2}}+\frac{\left(0.85 s_{\text {pre }}\right)^{2}}{n_{1}}}} \text { and } t_{2}=\frac{\bar{X}_{\text {post }}-1.15 \bar{X}_{\text {pre }}}{\sqrt{\frac{s_{\text {post }}^{2}}{n_{2}}+\frac{\left(1.15 s_{\text {pre }}\right)^{2}}{n_{1}}}}
$$

The null hypothesis, $H_{0}$, will be rejected if $t_{1}$ is "too small" or if $t_{2}$ is "too large". We constructed a test based on an overall level of significance of $\alpha=0.05$.

Specifically, the null hypothesis, $H_{0}$, will be rejected based on the following quantiles of a Student's $t$ distribution:

$$
\text { Reject } H_{0} \text { if: } t_{1} \leq t_{\alpha, v_{1}}=t_{0.05, v_{1}} \text { or } t_{2} \geq t_{1-\alpha, v_{2}}=t_{0.95, v_{2}}
$$

For simplicity, we assumed that $\sigma_{\text {pre }}=\sigma_{\text {post }}\left(s_{\text {pre }}=s_{\text {post }}\right)$. The associated degrees of freedom are estimated using the Welch-Satterthwaite [Ref. E.3] approximation when $n_{1}=n_{2}=n$ as:

$$
v_{1}=(n-1)\left(1+\frac{2 \cdot 0.85^{2} s_{\text {pre }}^{2} s_{\text {post }}^{2}}{0.85^{4} s_{\text {pre }}^{4}+s_{\text {post }}^{4}}\right) \text { and } v_{2}=(n-1)\left(1+\frac{2 \cdot 1.15^{2} s_{\text {pre }}^{2} s_{\text {post }}^{2}}{1.15^{4} s_{\text {pre }}^{4}+s_{\text {post }}^{4}}\right)
$$

which results in $v_{1}=17.54$, and $v_{2}=17.66$.

The resulting $t$ quantiles defining the rejection criteria are $t_{0.05,17.54}=-1.74$ and $t_{0.05,17.66}=1.74$, which leads to the following rule:

Reject $H_{0}$ if: $t_{1} \leq-1.74$ or $t_{2} \geq 1.74$

If the null hypothesis cannot be rejected, then the instrument's pre-test and post-test responses have not been shown to differ by more than $15 \%$ and thus the instrument is considered acceptable.

\section{E.3 Test Evaluation}

The quality of a hypothesis test can be characterized by its propensity to make the correct decision. In this case, a correct decision is to accept an instrument when $\mu_{\text {post }}$ is within $15 \%$ of $\mu_{\text {pre }}$ and reject an instrument when $\mu_{\text {post }}$ is beyond $15 \%$ of $\mu_{\text {pre. }}$ The red curve in the top panel of Figure 8 illustrates the performance of the above described hypothesis test by displaying the probability of accepting an instrument as a function of $\mu_{\text {post. }}$ In the example illustrated in Figure $8, \mu_{\text {pre }}$ is 100 , thus the acceptable region is $85 \leq \mu_{\text {post }} \leq 115$ and unacceptable region is $\mu_{\text {post }}<85$ or $\mu_{\text {post }}>115$; these boundaries are displayed by vertical dotted lines. The ideal hypothesis test would have a $0 \%$ probability of accepting an instrument when $\mu_{\text {post }}$ is outside these bounds and a $100 \%$ probability of accepting an instrument when $\mu_{\text {post }}$ is inside these 
bounds. With a fixed and limited test sample size $\left(n_{1}=n_{2}=10\right)$ we are unable to obtain these ideal properties, though the hypothesis test approaches this ideal step-like behavior as the coefficient of variation is reduced. This is illustrated by the curves in the middle and bottom panels of Figure 8.

These observations regarding the size of the coefficient of variation can be alternately stated as the ability to detect a significant change in the instrument performance due to the influence quantity (and correctly reject such an instrument) decreases as the coefficient of variation increases. In other words, when an instrument displays a large coefficient of variation, the proposed test cannot detect a significant effect due to the influence quantity and the instrument would be erroneously deemed as satisfying the requirement. For this reason, the test setup must be such that the strength of the radiation field allows the radiation detection instruments to display a coefficient of variation less than a specified requirement. If the coefficient of variation requirement cannot meet, then the number of pre-test and post-test instrument readings must be increased to compensate, else the tests on the influence quantities should not be carried out as the results will be uninformative and misleading.

In addition to altering the radiation field to reduce the coefficient of variation, adjusting the level of significance can also impact the quality of the hypothesis test. The green and blue curves in each panel of Figure 8 illustrate the performance of hypothesis tests with $\alpha=0.10$ and $\alpha=0.20$ levels of significance.

From the red curve in the top panel of Figure 8, it is seen that the above described hypothesis test provides a high probability of accepting an acceptable instrument at all $\mu_{\text {post }}$ values between 85 and 115, but the probability of accepting an unacceptable instrument can be considerably large - even at $\mu_{\text {post }}$ values beyond $25 \%$ of $\mu_{\text {pre. }}$. By increasing the level of significance to $\alpha$ $=0.10$ (green curves) and $\alpha=0.20$ (blue curves), the probability of accepting an acceptable instrument deceases slightly near the edges of the acceptance region, but modest gains are made in decreasing the probability of accepting unacceptable instruments.

Based on the observation from recent testing that the typical coefficient of variation value was between $2 \%$ and $6 \%$, and the observed performance of the various hypothesis tests illustrated in Figure 8, it is recommended that the test setup be required such that the radiation field produced allows the radiation detection instruments to display a coefficient of variation in their pre-test readings to be no greater than $8 \%$, and that the hypothesis test be carried out at the $\alpha=0.20$ level of significance. The criteria in Equation E.3 is thus updated such that the instrument performance is accepted if $t_{1} \geq-0.86$ and $t_{2} \leq 0.86$ where $t_{1}$ and $t_{2}$ are the test statistics calculated according to Equation E.2. These recommendations are aimed at creating a test that balances the desires to maximize the probability of accepting acceptable instruments and minimize the probability of accepting unacceptable instruments while remaining cognizant of the practical limitations of the test laboratories and the cost of testing. 

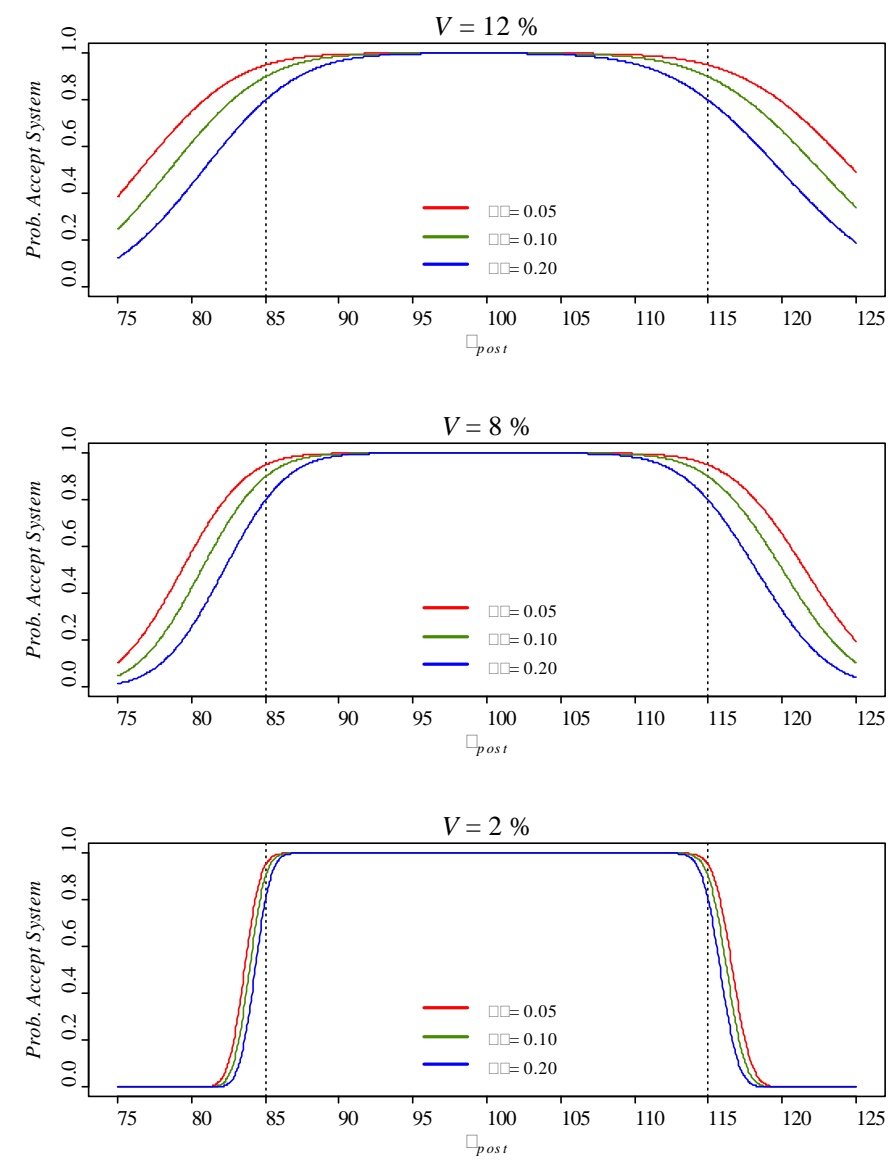

Figure 8: Estimated probability of accepting an instrument under the hypothesis test when $\mu_{\text {pre }}=100$ and $\mathrm{n}_{1}=\mathrm{n}_{2}=10$ for $\mathrm{V}=12 \%$ (top), $\mathrm{V}=8 \%$ (middle), and $\mathrm{V}=2 \%$ (bottom) with levels of significance $\alpha=0.05$, 0.10 , and 0.20 .

\section{E.4 Larger Coefficient of Variations Values}

If an instrument cannot achieve the required $8 \%$ coefficient of variation, the number of readings must be appropriately increased to maintain the same level of scrutiny as provided by the above proposed test with $n=10, V \leq 8 \%$, and $\alpha=0.20$. The ability of the test to identify an unacceptable instrument decreases as the coefficient of variation increases. This is illustrated in Figure 8, by the flattening of the curves as the coefficient of variation increases. By appropriately increasing the number of readings, $n$, we can achieve the same performance as that of the proposed test (blue curve, center panel of Figure 8). As the number of readings is altered, the rejection criteria in Equation E.3 must also be adjusted. Table E.1 provides the required number of readings and associated rejection criteria as the coefficient of variation changes from $8 \%$ to $25 \%$.

Table E.6: The required number of measurements and associated test criteria to maintain equivalent level of scrutiny when the coefficient of variation exceeds the required maximum of $8 \%$.

\begin{tabular}{|c|c|c|c|}
\hline $\boldsymbol{V}(\mathbf{\%})$ & Required $\boldsymbol{n}$ & $\boldsymbol{t}_{\mathbf{1}}$ criteria & $\boldsymbol{t}_{\mathbf{2}}$ criteria \\
\hline 8 & 10 & -0.86 & 0.86 \\
\hline
\end{tabular}




\begin{tabular}{|c|c|c|c|}
\hline 9 & 13 & -0.86 & 0.86 \\
\hline 10 & 16 & -0.85 & 0.85 \\
\hline 11 & 19 & -0.85 & 0.85 \\
\hline 12 & 22 & -0.85 & 0.85 \\
\hline 13 & 26 & -0.85 & 0.85 \\
\hline 14 & 30 & -0.85 & 0.85 \\
\hline 15 & 35 & -0.85 & 0.85 \\
\hline 16 & 39 & -0.85 & 0.85 \\
\hline 17 & 44 & -0.85 & 0.85 \\
\hline 18 & 50 & -0.85 & 0.85 \\
\hline 19 & 55 & -0.85 & 0.85 \\
\hline 20 & 61 & -0.84 & 0.84 \\
\hline 21 & 68 & -0.84 & 0.84 \\
\hline 22 & 74 & -0.84 & 0.84 \\
\hline 23 & 81 & -0.84 & 0.84 \\
\hline 24 & 88 & -0.84 & 0.84 \\
\hline 25 & 96 & -0.84 & 0.84 \\
\hline
\end{tabular}

\section{E.5 References}

[E.1] Casella, G., \& Berger, R. L. (2002). Statistical Inference, Second Edition. Pacific Grove, CA: Duxbury.

[E.2] DeGroot, M. H. (1989). Probability and Statistics (Second ed.). Reading, MA: Addison-Wesley.

[E.3] Satterthwaitte, F. E. (1946). An Approximate Distribution of Estimates of Variance Components. Biometrics Bulletin, 2(6), 110-114. 